\title{
Use of West Virginia permanent traffic recorder data to develop factors for traffic and truck variation
}

Jacob Scott D'Angelo

West Virginia University

Follow this and additional works at: https://researchrepository.wvu.edu/etd

\section{Recommended Citation}

D'Angelo, Jacob Scott, "Use of West Virginia permanent traffic recorder data to develop factors for traffic and truck variation" (2002). Graduate Theses, Dissertations, and Problem Reports. 1224.

https://researchrepository.wvu.edu/etd/1224

This Thesis is protected by copyright and/or related rights. It has been brought to you by the The Research Repository @ WVU with permission from the rights-holder(s). You are free to use this Thesis in any way that is permitted by the copyright and related rights legislation that applies to your use. For other uses you must obtain permission from the rights-holder(s) directly, unless additional rights are indicated by a Creative Commons license in the record and/ or on the work itself. This Thesis has been accepted for inclusion in WVU Graduate Theses, Dissertations, and Problem Reports collection by an authorized administrator of The Research Repository @ WVU. For more information, please contact researchrepository@mail.wvu.edu. 


\title{
Use of Kest Virginia Permanent Traffic Recorder Data to Develop Factors for Traffic and Truck Variation
}

\author{
By \\ Jacob S. D’Angelo \\ Thesis submitted to the \\ College of Engineering and Mineral Resources \\ at West Virginia University \\ in partial fulfillment of the requirements \\ for the degree of \\ Master of Science \\ in \\ Civil Engineering \\ Ronald W. Eck, Ph.D., Chair \\ Lloyd James French III, Ph.D. \\ Darrell R. Dean, Ph.D. \\ Department of Civil and Environmental Engineering \\ Morgantown, West Virginia \\ 2002
}

Keywords: Traffic Monitoring, Axle Correction Factors, Peak Hour Volume,

Design Hour Volume, and Truck Factors 


\section{ABSTRACT \\ Use of West Virginia Permanent Traffic Recorder Data to \\ Develop Factors for Traffic and Truck Variation \\ Jacob S. D’Angelo}

The purpose of this study was to use data collected from the 52 permanent count stations located throughout the state to develop four sets of factors that would assist the West Virginia Department of Transportation (WVDOT) in the management and engineering of the roadways in West Virginia.

The objectives of this study were to:

1) Establish correction factors that can be applied to the short-term single pneumatic tube traffic count stations to adjust for the effect of three or more axle trucks on the volume counts.

2) Establish factors that use the peak hour volume (PHV) to estimate the design hour volume (DHV).

3) Establish factors that relate the percentage of trucks in the average daily traffic (ADT) to a) the percentage of trucks in the peak hour and b) the percentage of trucks in the hours used by the WVDOH in conducting manual classification counts.

Using analysis of variance (ANOVA analysis) to determine statistical significance, the factors were approximately aggregated and either reported by year, month of the year, quarter, or day of the month. The axle correction factors were reported by functional class by year, except rural interstates. Due to a significant difference in the first quarter, one factor was reported for the first quarter and another factor was reported for the rest of the year. PHV to DHV factors were reported by day of the month for each functional classification. The factors relating percent of trucks in the ADT to a) the percentage of trucks in the peak hour and b) the percentage of trucks in the hours used by the WVDOH in conducting manual classification counts were reported by rural heavy truck route, urban heavy truck route, or "other" routes due to the insignificant variability within the normal functional class groupings. The only variability detected was between the interstates and the non-interstate roadways. The detailed tables containing these factors are presented in the report. 


\section{VITA}

The author, Jacob D’Angelo, was born April 16, 1979 in Parkersburg, West Virginia, where he lived until moving to Elkins, West Virginia at the age of 11. The author graduated from Elkins High School in the spring of 1997 and was accepted to attend West Virginia University in the fall of 1997. Graduating magna cum laude, Jacob received his bachelor's degree in Civil and Environmental Engineering in the spring of 2001. The author was then accepted to attend graduate school at West Virginia University, specializing in the transportation field of civil engineering. By completing graduate-level courses while finishing his master's degree, his course requirements for a master's degree were met in December 2001. 


\section{ACKNOWLEDGEMENTS}

The author would like to thank the West Virginia Division of Highways for their

financial support of this project. The interest and continued technical support throughout the duration of this research project provided by Jerry Legg is sincerely appreciated. Also, a word of thanks to the Department of Civil and Environmental Engineering at West Virginia University for the opportunity to continue my education and broaden my knowledge in the field of Civil Engineering. The author would like to thank the faculty and staff of the CEE department, with a special thanks to Dr. Ronald Eck, Dr. Jim French, and Dr. Darrell Dean for their guidance throughout this research project. 


\section{TABLE OF CONTENTS}

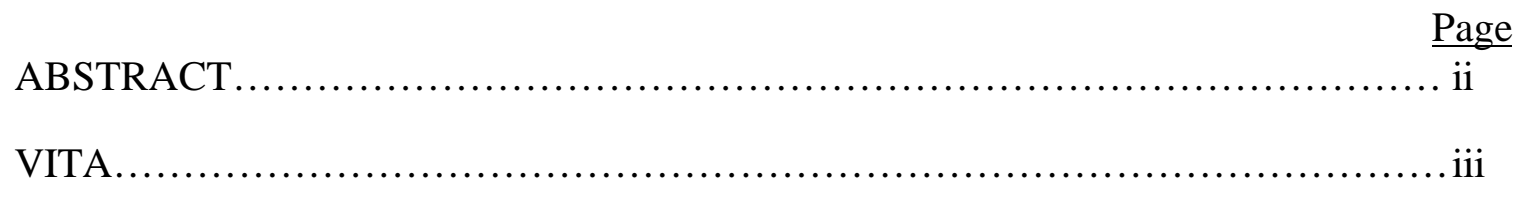

ACKNOWLEDGEMENTS ................................................. iv

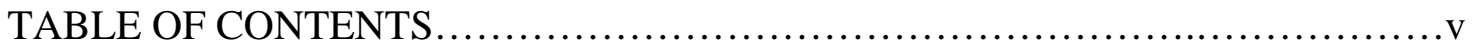

LIST OF TABLES......................................................... vii

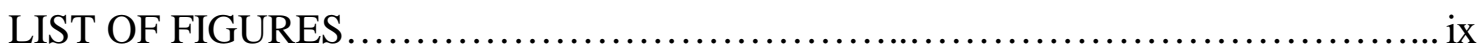

Chapter 1

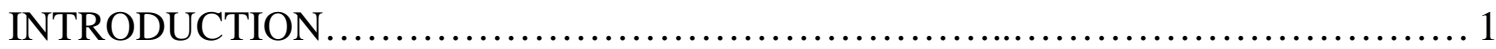

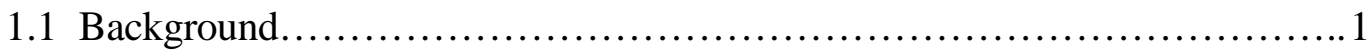

1.2 Problem Statement.................................................. 4

1.3 Project Objectives................................................... 7

1.4 Organization of Report............................................ 7

Chapter 2

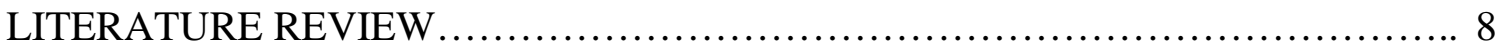

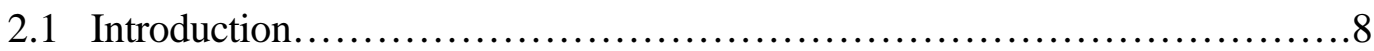

2.2 Traffic Monitoring Programs........................................ 9

a. Procedure Guidelines......................................... 9

b. Permanent and Short-Term Counts............................... 10

c. Error-Checking Methodologies............................. 12

2.3 Developing Axle Correction Factors Using Vehicle Classification Counts..14

a. Overview.................................................. 14

b. Determination of Axle Adjustment Factors...................... 15

c. Grouping the Data Collection Sites............................ 17

d. Variation of Factors with Time............................... 20

2.4 Percentage of Trucks in Traffic Stream.............................. 25

2.5 Relationship of Design Hour Volume and Peak Hour Volume.............. 29

2.6 Other States' Programs............................................ 29

2.7 Concluding Remarks............................................. 32 
Chapter 3

METHODOLOGY

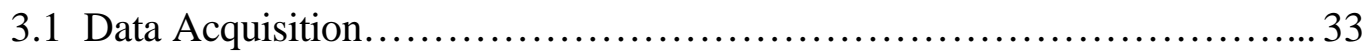

3.2 Axle Correction Factor Procedure..................................... 36

3.3 Estimating Design Hour Volume..................................... 40

3.4 Relationship of \% Trucks in the ADT to \% Trucks in the Peak Hour...... 44

3.5 Relationship of $\%$ Trucks in the ADT to \% Trucks in the ..................46 Manual Count Hour

Chapter 4

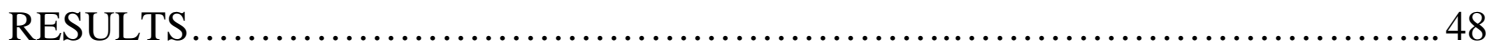

4.1 Axle Correction Factor.............................................. 48

4.2 PHV to DHV Factor.................................................. 50

$4.3 \%$ Trucks in the ADT to \% Trucks in the Peak Hour Factor................. 53

$4.4 \%$ Trucks in the ADT to \% Trucks in the Manual Count Hours Factor...... 54

Chapter 5

CONCLUSIONS AND RECOMMENDATIONS................................57

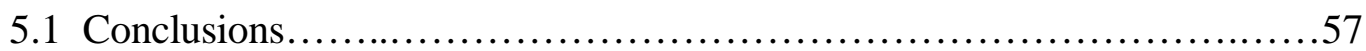

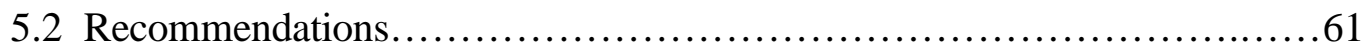

5.3 Implementation...................................................... 61

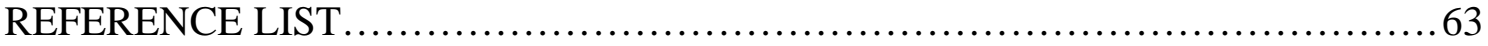

APPENDICES

APPENDIX A. AXLE CORRECTION FACTOR SUMMARIES BY ................ 64 DAY OF YEAR, BY MONTH, AND BY QUARTER

APPENDIX B. PHV TO DHV FACTOR SUMMARIES BY ….................... 66 DAY OF YEAR, BY MONTH, AND BY QUARTER

APPENDIX C. PERCENT TRUCKS IN ADT TO PERCENT TRUCKS ............ 68 IN PEAK HOUR FACTOR SUMMARIES BY DAY OF YEAR, BY MONTH, AND BY QUARTER

APPENDIX D. PERCENT TRUCKS IN ADT TO PERCENT TRUCKS ............70 IN MANUAL COUNT HOUR FACTOR SUMMARIES BY DAY OF YEAR, BY MONTH, AND BY QUARTER

APPENDIX E. FACTORS DEVELOPED USING ONLY FRIDAY, ............. 72 SATURDAY, AND SUNDAY DATA 


\section{LIST OF TABLES}

Table

Page

1.1 - List of West Virginia Permanent Traffic Count Stations..................... 8

2.1 - Average Number of Axles per Vehicle Class (Source: FHWA, 2001)........... 16

2.2 - Roadway Groups Recommended by the Traffic Monitoring Guide ............. 18

2.3 - Factors $\left(\mathrm{B}_{\mathrm{ij}}\right)$ from 1975 WVDOH Study Relating PHV to DHV ............... 22

2.4 - 1975 Factors (Bi) Relating Percent Trucks ADT to Percent Trucks in ........ 23

Peak Hour Volume

2.5 - PENNDOT'S Traffic Pattern Groupings..................................... 30

2.6 - Axle Correction Factors Reported by PENNDOT $\ldots \ldots \ldots \ldots \ldots \ldots \ldots \ldots \ldots \ldots \ldots . \ldots . \ldots \ldots$

2.7 - Michigan DOT's Traffic Pattern Groupings............................... 31

3.1 - Number of Sites in Each Functional Class.................................... 33

3.2 - Preliminary ANOVA Analysis for the Axle Correction Factor.................. 38

3.3 - ANOVA Analysis Summary for Axle Correction Factor with Friday, ........... 39

Saturday, and Sunday Removed

3.4 - Preliminary ANOVA Analysis for the PHV to DHV Factor.................... 42

3.5 - ANOVA Analysis Summary for PHV to DHV Factor with Friday, .............43

Saturday, and Sunday Removed

3.6 - Relationship of AADT and PHV-DHV Factor.............................. 45

4.1 - Axle Correction Factor Results.......................................... 48

4.2 -West Virginia and Pennsylvania Axle Correction Factors........................ 50

4.3 - DHV Summary by Day of the Month.................................. 51

4.4 - Factors Relating Percent Trucks in ADT to Percent Trucks in Peak Hour....... 53 
4.5 - Factors Relating Percent Trucks in ADT to Percent Trucks in Manual .......... 55

Count Hours

4.6 -Comparison of WVDOH 1995-1996 Data and PENNDOT 2001 Data ........... 56 


\section{LIST OF FIGURES}

Figure $\quad$ Page

2.1 - Basic Time of Day Patterns in Traffic Volume (FHWA, 2001).................26

2.2 - Typical Hour of the Day Travel Patterns for Large Trucks (FHWA, 2001)....... 27

3.1 - Example of Determination of Design Hour Volume........................... 41 


\section{Chapter 1}

\section{INTRODUCTION}

\subsection{Background}

A traffic-monitoring program consists of several facets such as data collection of traffic volume, vehicle classification, and truck weight studies. Data collection includes the use of portable, short duration counters and permanent, continuous counters to obtain the necessary traffic data. Data collected through a traffic-monitoring program is used widely throughout state highway agencies. Traffic data such as traffic volume, vehicle classification, and truck weight may be used in applications such as project planning, pavement design, safety analysis, capacity analysis, and air quality assessment (AASHTO, 1992). Because of the role that traffic data play in decision making and consequently in the allocation of funds for highway improvements, it is important that current traffic parameters be used.

The process of traffic monitoring begins with the collection of data from continuous counters throughout the state. These collected data are then used to correct or expand the data collected on a short-term basis from short duration counters. In West Virginia, the Traffic Analysis Section of the West Virginia Department of Transportation collects and compiles traffic data for the state-owned highways. The Department collects traffic volume and classification data continuously at 52 permanent counter locations statewide. These sites and their locations and key characteristics are shown in Table 1.1. These 
Table 1.1 - List of West Virginia Permanent Traffic Count Stations

\begin{tabular}{|c|c|c|c|c|}
\hline Site Number & Location & Description & Functional Class & Number of Lanes \\
\hline & & & & \\
\hline 1 & I-64 & 1.2 miles west of WV 20 & 1 & 4 \\
\hline 2 & $1-64$ & 1.5 miles west of CO 60/89 & 11 & 4 \\
\hline 3 & $1-77$ & 2.2 miles north of $\mathrm{CO} 15$ & 1 & 4 \\
\hline 401 & $\mathrm{I}-77 \mathrm{NB}$ & 1.2 miles south of WV 14 & 1 & 3 \\
\hline 402 & I-77 SB & 1.2 miles south of WV 14 & 1 & 3 \\
\hline 5 & $1-79$ & 0.8 miles north of US 19 & 1 & 4 \\
\hline 6 & $1-79$ & 0.2 miles south of WV 131 & 1 & 4 \\
\hline 7 & WV 2 & 2.9 miles north of $\mathrm{CO} 2 / 2$ & 2 & 2 \\
\hline 8 & US 19 & 0.2 miles north of CO $19 / 45$ & 2 & 4 \\
\hline 9 & US 50 & 1.0 miles east of $\mathrm{l}-77$ & 2 & 4 \\
\hline 10 & US 60 & 0.5 miles west of $\mathrm{CO} 60 / 4$ & 2 & 2 \\
\hline 11 & US 119 & 0.8 miles south of WV 3 & 2 & 4 \\
\hline 12 & WV 131 & 1.2 miles north of US 50 & 6 & 2 \\
\hline 13 & WV 152 & 0.3 miles north of $\mathrm{CO} 52 / 1$ & 6 & 2 \\
\hline 14 & US 33 & 1.1 miles east of $\mathrm{CO} 13$ & 6 & 2 \\
\hline 15 & US 35 & 1.0 miles north of $\mathrm{CO} \mathrm{CO} 27$ & 6 & 2 \\
\hline 16 & US 52 & 0.5 miles east of $\mathrm{CO} 52 / 17$ & 6 & 2 \\
\hline 17 & US 119 & 1.1 miles south of CO 119.90 & 6 & 2 \\
\hline 18 & US 219 & 1.4 miles north of CO 56 & 6 & 2 \\
\hline 19 & $\mathrm{CO} 21$ & 0.4 miles north of $\mathrm{CO} 33 / 12$ & 7 & 2 \\
\hline 20 & US 220 & 1.5 miles south of CO $220 / 4$ & 7 & 2 \\
\hline 21 & WV 28 & 0.2 miles west of CO 41 & 7 & 2 \\
\hline 22 & US 19 & 1.5 miles north of CO $19 / 36$ & 7 & 2 \\
\hline 23 & US 19 & 0.4 miles south of $\mathrm{CO} 40 / 2$ & 7 & 2 \\
\hline 24 & US 40 & 0.2 miles west of $\mathrm{CO} 41$ & 7 & 2 \\
\hline 25 & US 60 & 0.1 miles west of $\mathrm{CO} 25 / 1$ & 7 & 2 \\
\hline 26 & $1-64$ & 1.5 miles east of US 52 & 11 & 4 \\
\hline 27 & $1-64$ & 2.2 miles west of WV 622 & 11 & 4 \\
\hline 29 & $1-70$ & 4.0 miles west of $\mathrm{CO} 41$ & 11 & 4 \\
\hline 30 & $1-77$ & 2.2 miles south of WV 3 & 11 & 4 \\
\hline 31 & WV 2 & 0.2 miles north of WV 2 ALT & 12 & 4 \\
\hline 32 & US 50 & 0.4 miles west of $\mathrm{CO} 50 / 40$ & 12 & 4 \\
\hline 33 & WV 10 & 0.4 miles south of I-64 & 14 & 2 \\
\hline 34 & WV 25 & 1.0 miles west of WV 622 & 14 & 2 \\
\hline 351 & US 52 WB & 0.7 miles west of $\mathrm{CO} 29$ & 14 & 2 \\
\hline 352 & US 52 EB & 0.7 miles west of CO 29 & 14 & 2 \\
\hline 36 & US 60 & 0.1 miles west of $\mathrm{CO} 85$ & 14 & 4 \\
\hline 37 & US 11 & 1.0 miles south of WV 45 & 16 & 2 \\
\hline 38 & WV 61 & 1.4 miles south of I-77 KC & 17 & 2 \\
\hline 39 & $1-64$ & 2.5 miles west of WV 34 & 1 & 4 \\
\hline 40 & WV 114 & 0.2 miles north of CO $114 / 1$ & 16 & 2 \\
\hline 41 & US 119 & 0.1 miles north of CO $119 / 16$ & 16 & 2 \\
\hline 42 & $1-64$ & 1.7 miles south of WV $114 \mathrm{I}$ & 11 & 4 \\
\hline 43 & WV 44 & 0.5 miles south of US 119 & 7 & 2 \\
\hline 44 & WV 94 & 0.5 miles north of WV 3 & 6 & 2 \\
\hline 45 & WV 7 & 0.2 miles east of WV 2 & 7 & 2 \\
\hline 46 & US 250 & 0.7 miles south of $\mathrm{CO} 56 / 1$ & 7 & 2 \\
\hline 47 & $1-77$ & 1.0 miles south of WV 112 & 1 & 4 \\
\hline 48 & WV 20 & 0.1 miles west of $\mathrm{CO} 20 / 12$ & 6 & 2 \\
\hline 49 & WV 92 & 2.5 miles south of WV 39 & 6 & 2 \\
\hline 50 & $1-81$ & 1.6 miles south of WV 44 & 1 & 4 \\
\hline 51 & WV 20 & 0.6 miles south of WV 55 & 7 & 2 \\
\hline 53 & $1-68$ & 1.0 miles west of WV 26 & 1 & 4 \\
\hline
\end{tabular}


stations are permanent traffic recorders; devices that are embedded in the roadway that count traffic passing over the device. These devices can record information such as vehicle type, weight, speed, and volume of traffic. The type of a permanent counter used in West Virginia, and typically in the United States, is an arrangement of inductive loops that are installed in the pavement. If weight data are needed, weigh-in-motion devices are added to the inductive loop arrangement.

Short duration data collection takes place at over 2,500 locations annually. There are a total of 7,500 short-term count stations throughout the state. A short-term count is performed once every three years at each location. Data for short duration counts are collected either manually or by temporary traffic counters such as pneumatic tube counters. Pneumatic tube counters are devices that are placed on the roadway for a short period of time to record the number of axles that travel over the device. These devices record only the number of axles that travel over it; they have no ability to distinguish between vehicle types, speed, or weight. Manual counts represent a small fraction of the total short-term counts performed in West Virginia.

Permanent count stations collect and record data continuously throughout the year, where short-term counters collect data for short time periods, usually 24 or 48 hours. Thus, a factor needs to be applied to the short-term count results to expand the results to provide additional information such as PHV to DHV or correct the results due to short-comings in the collection process such as the axle correction factor to correct short-term pneumatic tube counts. The information gathered from the permanent count stations is used to determine the factors that are applied to the short duration counts. A factor is a value by 
which the short-term count is multiplied in order to correct or expand the short-term count results. An example application would be as follows:

$$
\begin{aligned}
\text { actual number of vehicles }= & \text { number of vehicles determined by short-term counter } \\
& * \text { axle correction factor }
\end{aligned}
$$

\subsection{Problem Statement}

In 1975, the Traffic Analysis Section of the WVDOH-Advanced Planning Division (1975) conducted three studies to develop adjustment factors that could be applied to the short duration counts. The study results were reported in three separate reports and have received extensive use since their development. One of the studies, Determination of a Truck Adjustment Factor for ATRs (Traffic Analysis Section, May 1975), was performed to establish a factor that could be applied to the raw counts from short-term traffic recorders to account for the effect of vehicles with 3 or more axles. The pneumatic tube short-term counters alone cannot be used to accurately estimate the volume of traffic that traveled over the tube because they simply count axles rather than number of vehicles.

Another study was The Development of a Method of Estimating Design Hour Volume (Traffic Analysis Section, December 1975). The study's purpose was “to establish a factor by which peak hour volume could be converted to an estimate of design hour volume." This study provided a factor by which the largest volume occurring during one hour of the short-term count (peak hour) could be multiplied to estimate the design hour volume on that roadway. The factor took into account the roadway's AADT and the season during which the short-term count was performed. 
The other study, The Relationship of the Percentage of Trucks in the Average Daily Traffic (ADT) to the Percentage of Trucks in the Peak Hour Volume (PHV) (Traffic Analysis Section, February 1975), was performed because through observation, they expected that the percentage of trucks in the AADT was normally greater than the percentage of trucks in the peak hour volume. It was generally understood that the temporal distribution of the percentage of trucks was not necessarily uniform over a 24hour period, and that truck flow did not necessarily peak during the general vehicle peak. These elements combine to make the percentage of trucks in the peak hour less than the overall percentage of trucks in daily traffic. However, traffic-counting techniques that utilize manual classification are typically performed for durations shorter than 24-hours. As a result, the WVDOT used vehicle count and classification data that were collected manually to develop factors that relate the percentage of trucks in the peak hour to the percentage of trucks in the AADT.

These studies are now over 25 years old. It is likely that changing travel patterns such as increased vehicle miles traveled or changing demographics such as more vehicles per household and an increase in the percentage of working females in West Virginia have reduced the validity of the results of these studies for use in the traffic analyses of the present day and the planning horizon. Also, the travel patterns of large trucks have changed greatly over the past 25 years. In the past, goods were stored in warehouses throughout the country and trucks were used to deliver goods to and from these warehouses. Today, goods are delivered from the factory to the customer in a just-intime fashion. This has changed the operational pattern of trucks. They can no longer 
travel predominately at night to avoid heavy traffic during the day. Another factor related to truck operations has been the completion of the Interstate Highway System in West Virginia. In 1975, the system was incomplete in West Virginia with many missing links that were not attractive as through routes for commercial vehicles.

These studies had a common thread in that they were performed primarily using traffic count data from permanent count stations in West Virginia. Currently, traffic counts are continuously collected at permanent recorder stations; therefore, these studies can essentially be repeated with a present day database. It would be desirable to determine the above-mentioned parameters using current traffic count data from West Virginia permanent counter stations.

There are additional parameters, which can be obtained from the permanent traffic recorder data that would be of interest to WVDOT planners. One of these is the determination of factors that relate the percentage of trucks in the average daily traffic to the percentage of trucks in the hours currently used by the WVDOT in conducting manual classification counts. This factor will expand the percentage of trucks counted during a manual classification count so that a more accurate estimation of the percentage of trucks traveling on the roadway during an entire day can be derived. This factor is needed for pavement design, capacity analysis, and may be used to compare potential roadway projects. The design of pavements depends both on the loads the pavement will be exposed to, and the number of repetitions of the loads. Capacity analysis uses both the overall traffic volume and the percent trucks in the overall volume to determine, among 
other things, the number of lanes needed to provide a desired level of service. Project selection may depend on the overall traffic volume and the percent trucks traveling on the roadway. For these reasons the highway designer needs to know the percentage of trucks in the ADT.

\subsection{Project Objectives}

The objectives of this study were to:

1) Establish correction factors that can be applied to the raw data from axlecounting single pneumatic tube traffic count stations to adjust for the effect of trucks with three or more axles on the volume counts.

2) Establish factors that use the peak hour volume to estimate the design hour volume.

3) Establish factors that relate the percentage of trucks in the ADT to a) the percentage of trucks in the peak hour and b) the percentage of trucks in the hours used by the WVDOT in conducting manual classification counts.

\subsection{Organization of Report}

Chapter 1 has presented background to the problem and identified the problem and study objectives. Chapter 2 contains a summary of the literature reviewed to identify relevant information concerning the factors to be developed and the methods used. The literature review is followed by the methodology which is presented in Chapter 3. Project results are presented in Chapter 4. Conclusions, recommendations, and suggestions for implementation are discussed in Chapter 5. 


\section{Chapter 2 LITERATURE REVIEW}

\subsection{Introduction}

This chapter documents the literature reviewed relative to the factors developed for traffic and truck variation from data collected through the use of permanent traffic recorders and relates it to the current West Virginia Department of Transportation program. The scope of this literature review was limited to examination of the Federal Highway

Administration's (2001) Traffic Monitoring Guide and AASHTO's Guidelines for Traffic Data Programs (1992) since these serve as guidelines for states' traffic monitoring programs. The examination also included determining how two other states were following the recommendations set forth by FHWA and AASHTO. The previously mentioned factors studies performed by West Virginia Department of Highways in 1975 were reviewed to determine the procedures followed.

Techniques for collecting and analyzing traffic data are well established across the United States. The FHWA Traffic Monitoring Guide (2001), and the AASHTO Guidelines for Traffic Data Programs (1992) provide a good, up-to-date coverage of the topic and are used as guides by all states when performing traffic counts and interpreting the output data from these counts. The procedure guidelines from these documents are summarized here. This is followed by discussion of the procedures and methodologies relative to the specific data and factors of interest in this research. In addition, the three previous studies performed in 1975 by the West Virginia Department of Highways will be 
discussed. Pennsylvania DOT (Bureau of Planning and Research, 1999) and Michigan (Bureau of Transportation Planning, 2000) procedures were reviewed to analyze the procedures used by these two states to determine if they were consistent with the TMG and AASHTO guidelines.

\subsection{Traffic Monitoring Programs}

\section{2a Procedure Guidelines}

The Traffic Monitoring Guide 2001 (Federal Highway Administration, 2001) offers suggestions and standards to help improve and advance current programs with a view towards the future of traffic monitoring. In addition to including a basic structure for traffic monitoring, the TMG provides examples of how statewide data collection programs should be structured. It also describes the analytical logic behind that structure, and provides the information highway agencies need to maximize the efficiency of their traffic-monitoring program.

The American Association of State Highway and Transportation Officials (AASHTO) developed its Guidelines (AASHTO, 1992) because a general method of collecting and evaluating traffic data was needed. A common thread linking all states programs was needed because every state varies in their funding, staffing, and automating of traffic data programs. The following statement from the Guidelines itself, describes other concerns that the publication addresses: 
"The AASHTO Guidelines specifically addresses concerns of state transportation agencies. Also, they may be adopted for use by other governmental agencies and private firms. If state funds are used to support the traffic monitoring work of other agencies or firms, it is recommended that the Guidelines be followed to help ensure comparable traffic statistics."

The AASHTO Guidelines and the Traffic Monitoring Guide are very similar in their approach and recommendations relating to traffic monitoring programs. The differences between the two are as follows:

- The TMG contains the requirements set forth by the federal government which the states are required to follow in order to receive federal-aid funds.

- The AASHTO Guidelines supplements the FHWA Traffic Monitoring Guide and aids in the operational implementation of a state traffic data program.

\section{2b Permanent and Short-Term Counts}

The basic traffic-monitoring program of a state consists of short duration counts gathered by portable recorders and continuous counts collected by permanent recorders at a relatively small number of representative locations. The traffic on most roadways within a state is monitored at some point every 3 years or 6 years, depending on the roadway, but it would not be cost-effective to install a permanent counter on every roadway. The TMG (FHWA, 2001) recommended procedure for implementing a traffic-monitoring program includes the following steps: 
1) Determine the statewide needs for the traffic-monitoring program.

2) Determine what continuous collection data are needed for specific projects and what continuous collection exists or is planned for operational purposes.

3) Determine the available funding.

4) Prioritize the specific project locations.

5) Place counters at the specific project locations for which funding exists.

6) Determine how those data collection efforts can help meet statewide needs.

7) Determine additional number of additional continuous count locations needed to meet statewide needs.

8) Prioritize these remaining statewide needs locations.

9) Allocate counters to these statewide needs locations on the basis of their priority and the available funding.

10) If funding remains after statewide needs have been met, place additional continuous counters at the specific project sites for which counters are currently not allocated.

The Traffic Monitoring Guide (FHWA, 2001) and the AASHTO Guidelines (1992) both discuss the development of an axle correction factor, but the other factors developed in this study are not mentioned. The documents mention that traffic volume, vehicle classification, and truck weight data are all part of a traffic-monitoring program, but the other factors developed in this study are not discussed. 
The short duration counts are usually collected for 48 -hours at a large number of locations within the state to provide coverage. Permanent counters are installed at representative locations throughout the state to provide time-of-day, day-of-week, and seasonal travel patterns, all of which allow the development of factors needed to correct or expand the short-term count data into accurate estimates of annual traffic conditions. An example of data correction would be a factor developed by using information provided by a group of permanent count stations that could be applied to short-term pneumatic tube traffic counts to correct for the effect of three or more axle trucks on the volume counts. An example of a factor developed to expand on a short-term count would be a PHV to DHV factor that would allow an agency to perform a 48 hour count, determine the PHV which occurred during that 48 hours, and applying the factor to determine the DHV on the roadway.

\section{2c Error-Checking Methodologies}

According to the Traffic Monitoring Guide (FHWA, 2001), two types of error are possible in collecting and analyzing traffic data. The two types of error are 1) errors in collection, and 2) errors in editing. A wide range of factors including power failure, recorder malfunction, and detector malfunction are sources of invalid data and missing data from the permanent counters. The errors resulting from these malfunctions include missing days and/or missing hours of data, negative numbers included in the figures, and vehicle classification errors. How these errors are handled can have a major impact in the 
validity of the factors generated. Depending on the handling of these errors, errors in the editing process can result.

Both documents stated that, in terms of short-term counts, the minimum data requirement is a duration of 48 hours. If there is found to be a problem in the data such as missing data due to equipment malfunction, it is recommended by AASHTO (1992) and the Traffic Monitoring Guide (FHWA, 2001) that the count be redone. When permanent counts are visually found to contain errors, there is not a correction process. The only manual step in editing permanent counter data is to review the data set for completeness and to exclude data that has been rendered invalid through a power failure or machine malfunction. The following statements from AASHTO (1992) address the issue of attempting to manually correct erroneous data:

"Some current traffic editing programs estimate missing or edit-rejected data. This practice, termed "imputation", is not recommended."

"Subjective editing procedures for identifying and imputing missing or invalid data are discouraged, since the efforts of such data adjustments are unknown and frequently bias the resulting estimates."

The AASHTO Guidelines (AASHTO, 2001) state that there should be a sufficient number of days of valid traffic measurements during a year to compute average traffic characteristics at the site. The number of days needed is determined by whether or not an 
automated editing process is used to evaluate the recorded data. If automated edits are performed, it is recommended that agencies adopt a one-day minimum of edit-accepted data for each day of the week and each month of the year. Until agencies have implemented automated edits, it is recommended by AASHTO that a two-day minimum for each day of the week, each month of the year, be adopted. These statements from AASHTO and supported by the TMG are to be strictly followed so that the procedure used to determine the necessary factors is valid and complies with the AASHTOrecommended procedure.

\subsection{Developing Axle Correction Factors Using Vehicle Classification Counts}

\section{3 a Overview}

According to the Traffic Monitoring Guide (FHWA, 2001), in the 1980's, the Federal Highway Administration (FHWA) developed a vehicle classification system containing thirteen (13) categories of vehicles. According to the TMG (FHWA, 2001), all states currently use this classification system or a similar variation. Permanent counters recognize the different vehicle classifications and record the number of vehicles in each category that traveled over the counter during the designated time period. Reporting of the data in fifteen-minute and one-hour time intervals are common. Axle corrections factors can be developed from these data to adjust axle counts to an accurate estimate of the actual number of vehicles which traveled over the tube counter. 
Permanent traffic recorders use two in-pavement inductive loops to record axle spacing and vehicle classification, as well as speed, date, and time. Portable devices using a single pneumatic tube axle sensor can only count the number of axles that travel over them. The data from the permanent counters are retrieved and processed, and factors are developed and used to correct the data collected from the short-term pneumatic tube axle counters.

\section{3b Determination of Axle Adjustment Factors}

An axle correction factor must be derived from the information provided by the permanent counters and applied to the short-term single pneumatic tube counter so its information can have validity and be useful to traffic engineers. The following statement, from the Traffic Monitoring Guide (FHWA, 2001), states the importance of performing an axle correction count to adjust permanent traffic volume counts using the chart of values included in the TMG manual.

"Where classification counts exist (particularly those that use the 13 FHWA classes), a much more accurate axle correction factor can be computed by assigning an average number of axles per vehicle for each vehicle on that road."

The conversion chart, found in the Traffic Monitoring Guide (FWHA, 2001), included as Table 2.1, lists the suggested values to be used for each vehicle class when calculating an axle adjustment factor. 
Table 2.1 - Average Number of Axles per Vehicle Class (Source: FHWA, 2001)

\begin{tabular}{|c|l|c|}
\hline $\begin{array}{c}\text { Vehicle } \\
\text { Class }\end{array}$ & \multicolumn{1}{|c|}{ Description } & $\begin{array}{c}\text { Average Number of Axles per } \\
\text { Vehicle }\end{array}$ \\
\hline 1 & Motorcycles & 2 \\
\hline 2 & Passenger Cars & 2 \\
\hline 3 & 4-Tire Single Unit Vehicle & 2 \\
\hline 4 & Buses & 2 \\
\hline 5 & 2-Axle, 6-Tire Single Unit Truck & 2 \\
\hline 6 & 3-Axle Single Unit Truck & 3 \\
\hline 7 & 4+ Axle Single Unit Truck & 4 \\
\hline 8 & 4 or Less Axle Single Trailer Truck & 4 \\
\hline 9 & 5-Axle Single Trailer Truck & 5 \\
\hline 10 & 6+ Axle Multi-Trailer Truck & 6 \\
\hline 11 & 5 or Less Axle Multi-Trailer Truck & 5 \\
\hline 12 & 6-Axle Multi-Trailer Truck & 6 \\
\hline 13 & 7+ Axle Multi-Trailer Truck & 7 \\
\hline
\end{tabular}

A number of recommendations found in the AASHTO Guidelines (1992) are relevant to the current WVDOT program:

1) Computed axle correction factors are to be used to correct all short-term counts.

2) There is a recommended process (weighted average) for deriving an axle correction factor.

The AASHTO Guidelines (1992) highlights the importance of developing axle correction factors and applying the factors to short-term counts. AASHTO (1992) also describes the steps necessary to perform an axle correction count, including the classes of vehicles to be used and the weighting mechanism to be utilized. 
"At each vehicle classification count site, the number of vehicles is totaled by each of the 13 FHWA vehicle classifications. The number of the vehicles in each classification is multiplied by the number of axles in the classification. These are summed, and divided by the total number of vehicles. This is the average number of axles per vehicle at the permanent counter site. This figure is summed for all similarly grouped count sites, and divided by the number of counters. The result is the group mean axles per vehicle."

\section{3c Grouping the Data Collection Sites}

Once information is gathered from all of the permanent traffic recorders throughout the state, sites are grouped so that they are statistically similar based on several factors. These factors include geography, roadway classification, recreational usage, and any other relevant variable that would allow the sites to by grouped in a statistically significant manner. The Traffic Monitoring Guide (FHWA, 2001) recognizes the difficulty involved with grouping sites, as can be seen by the following statement:

"The grouping process is made more difficult and error prone because the appropriate definition of a "group" changes depending on the characteristics being measured."

Grouping roadways once the factors are calculated from the permanent traffic counters is essential; for the short term counts will not all be taken from the same roadways from 
which the permanent counters were used. For this reason, groups of similar roadways need to be formed so that a short-term count can be related to a factor that relates to that particular type of roadway. The TMG (FHWA, 2001) recommends the groups shown in Table 2.2 as a minimum.

Table 2.2 -Roadway Groups Recommended by Traffic Monitoring Guide (FHWA, 2001)

\begin{tabular}{|c|c|}
\hline Recommended Group & HPMS Functional Code \\
\hline Interstate Rural & 1 \\
\hline Other Rural & $2,6,7,8$ \\
\hline Interstate Urban & 11 \\
\hline Other Urban & $12,14,16,17$ \\
\hline Recreational & Any \\
\hline
\end{tabular}

Testing the quality of the selected groups is a key aspect to any grouping procedure. The following statement from the TMG (FWHA, 2001) includes their recommended methods of testing the quality of the groups.

"The quality of a given factor group can be examined in two ways. The first is to graphically examine the traffic pattern present at each site in the group. Graphs give an excellent visual description of whether different data collection sites have similar travel patterns. The second method is to compute the mean and standard deviation for various factors that the factor group is designed to provide. If these factors have small amounts of deviation, the roads can be considered to have 
similar characteristics. If the standard deviations are large, the road groupings may need to be revised."

A number of observations found in the AASHTO Guidelines (1992) are relevant to the current WVDOT program. West Virginia, as previously mentioned, currently has 52 permanent traffic recorder stations located throughout the state on various classes of roadways. The data from these locations must be grouped together in a statistically sound manner to ensure the validity of the factors. Grouping the data collected involves two steps: The first step is to group the sites so that the most similar sites are in the same group. The second is to associate short-term count stations to the long-term permanent count groups. The AASHTO Guidelines (1992) recommend that when grouping the permanent count locations, the variability between permanent count locations within the same group should be minimized, while the variability found between groups of permanent count locations should be maximized. AASHTO (1992) also states that when forming the permanent counter locations into groups, the recommended rule-of-thumb is that there should be a minimum of five counters in each of the defined groups. Once the permanent count locations have been grouped in a statistically verified manner, the locations of short-term traffic counts must be associated with the defined groups of permanent count locations. If data fail to group according to functional classification, AASHTO (1992) recommends using a method of combining the functional classification of the roadway with the geographic location of the count site within the state to obtain a more effective grouping. 


\section{3d Variation of Factors with Time}

Two facets of time are relevant when discussing the variation of the factors derived in this study. First and foremost, 25 years has passed since the WVDOH last developed the factors relevant to this study. The passing of 25 years necessitates the need for the development of a new set of factors to be used in the design and analysis of the roadways of West Virginia. Second, travel patterns of vehicles vary based on time of the day, day of the week, and season of the year. The variance of travel patterns based on day of the week and season of the year is the reason for the factors being analyzed based on these time-related factors.

As mentioned in Chapter 1, in 1975, three studies were performed by the West Virginia Department of Highways to determine the following factors:

1) A truck adjustment factor for short-term counters

2) Estimating DHV by using the PHV

3) Estimating the \% Trucks in the ADT by using the \% Trucks in the PHV

In performing the truck adjustment factor study (Traffic Analysis Section, May 1975), 62 temporary stations were established for the purpose of the study, at which a short-term (8 to 24 hour) manual count and a longer count lasting from 24 hours to 7 days was performed. The percentage of trucks and traffic volume was used to classify the roadway as either an expressway/trunkline or feeder/local roadway. The results from the truck adjustment factor study were as follows: 


$$
\begin{aligned}
& \text { Actual count }=0.92974 *(\text { short-term count }) \text { for feeders and locals } \\
& \text { Actual count }=0.88589 *(\text { short-term count }) \text { for expressways and trunklines }
\end{aligned}
$$

In this case, as would be expected, the higher roadway classifications experience a greater volume of truck traffic. This 1975 study documented that the magnitude of the factor depends upon the type of highway on which the count was performed.

The data for the PHV to DHV study (Traffic Analysis Section, December 1975) was derived from the permanent traffic recorder record for the year 1972. Analysis of variance (ANOVA) was performed to determine if there was a significant difference in the factors developed using the PHV, the $10^{\text {th }}$ highest hourly volume and the $30^{\text {th }}$ highest hourly volume. This test determined that factors should be derived separately for the $10^{\text {th }}$ highest and $30^{\text {th }}$ highest hourly volumes. The study also determined that the Annual Average Daily Traffic (AADT) was a significant player in the factor's development. Separate factors were determined for roads with an AADT less than or equal to 500 vehicles, and roads with AADT greater than 500 vehicles. The equation used to derive the factor relating PHV to DHV can be found below and the resulting factors are reported in Table 2.3. 


$$
\mathrm{DHV}=\mathrm{B}_{\mathrm{ij}} *(\mathrm{PHV})
$$

where $\quad B_{i j}$ is the factor relating the PHV to the DHV from Table 2.3

$$
\begin{aligned}
\mathrm{i} & =1 \text { if } \mathrm{AADT} \\
& =2 \text { if } \mathrm{AADT}>500 \\
\mathrm{j} & =1,2,3,4 \text {; depending on the quarter the count was taken }
\end{aligned}
$$

\section{Table 2.3 - Factors $\left(B_{i j}\right)$ from 1975 WVDOH Study Relating PHV to DHV (Source: Traffic Analysis Section, December 1975)}

\begin{tabular}{|c||c||c|c|}
\hline & & $\mathrm{i}=1$ & $\mathrm{i}=2$ \\
\hline \hline $\mathrm{j}=1$ & Dec - Feb & 1.42257 & 1.3316 \\
\hline $\mathrm{j}=2$ & Mar - May & 1.32577 & 1.23895 \\
\hline $\mathrm{j}=3$ & Jun - Aug & 1.28892 & 1.20249 \\
\hline $\mathrm{j}=4$ & Sept - Nov & 1.23583 & 1.15346 \\
\hline
\end{tabular}

In the study estimating truck percentages (Traffic Analysis Section, February 1975), data were collected from manual classification counts performed 4 times a year (one each season) at seventeen truck weight stations. Analysis of variance found that there was a significant difference in the factors developed for each season, thus they were reported by season. The equation used is found below and the results found from the estimation of the \% Trucks in the ADT by using the \% Trucks in the PHV are reported in Table 2.4.

Percentage of trucks in ADT $=\mathrm{Bi} *$ Percentage of trucks in peak hour volume where $B_{i}$ is the seasonal factor from Table 2.4 


\section{Table 2.4 - 1975 Factors (Bi) Relating Percent Trucks in ADT to Percent Trucks in Peak Hour Volume}

\begin{tabular}{|c||c||c|}
\hline \multicolumn{2}{|l|}{ Quarter } & \multicolumn{1}{c|}{ Factor } \\
\hline \hline 1 & Dec - Feb & 1.57329 \\
2 & Mar - May & 1.53734 \\
3 & Jun - Aug & 1.23805 \\
4 & Sept - Nov & 1.32063 \\
\cline { 2 - 3 } &
\end{tabular}

The factors derived in this study (Traffic Analysis Section, February 1975) show that the ratio of the percentage of truck in ADT to percentage of trucks in PHV was greater in the first and second quarters, meaning that large trucks were traveling less during the day in these quarters. The third and fourth quarters consisted of factors lower than those reported for the first and second quarters. This indicated that either more trucks were traveling during the peak hour of travel or that less passenger cars were traveling in these months causing the percentage of trucks in the ADT to increase. However, June through November are months of high travel for passenger cars, thus negating the latter possibility.

The premise of updating the factors developed in 1975 is that traffic patterns have changed since that time. The K-factor (the ratio of design hourly volume to the average daily traffic, expressed as a percentage) is a performance measure of traffic that could be used to estimate the significance of the change in traffic patterns. Its variation over time also has direct implications for the PHV to DHV factor, since they both are used in estimating the design hourly volume from some other traffic volume. 
According to AASHTO, (2001) the K-factor, based on data obtained in a traffic count program, is developed and applied system-wide. In other cases, factors may be developed for different facility classes or different areas of an urban region, or both.

A study performed by in 1988 (Sharma and Oh, 1988) researched, among other things, what affects the value of the K-factor. The conclusions drawn from their research was that the K-factor is a function of the nature of travel (rural, urban, suburban, or recreational) and that the $\mathrm{K}$-factor remains relatively stable over time as long as the nature of travel remains the same. K-factor values plotted for a site from 1973 through 1985 showed that K-factor values decreased slightly as AADT increased, and then rose slightly when AADT decreased.

Another study performed in 1988 (Walters and Poe, 1988) stated how the K-factor varies depending on the distance from a central business district (CBD) of large cities in Texas. Their results showed that the K-factor decreased the closer to the CBD the measurement was taken, and increased the farther away from the CBD the measurement was taken. This was due to the fact that congestion was greatest in the $\mathrm{CBD}$ and that congestion decreased as traffic dispersed from the congested area. They also stated that the K-factor tends to decline over time as congestion on a roadway increases.

In spite of statements to the contrary in some published literature (Sharma and Oh, 1988), there is actually very little documented research concerning how K-factors have varied 
over time. (Walters and Poe, 1988) However, among the studies that were published, the following was learned about the variation of K over time:

- The K-factor can vary up to $35 \%$ over the course of one year for different sections of the same roadway.

- $\mathrm{K}$ values remain relatively stable over time.

- $\mathrm{K}$ values decrease when the facility reaches capacity during the peak hour.

Therefore, since vehicle-miles of travel and roadway congestion has continually increased over the last several decades, it can be concluded that K-values in general should be lower now than in 1975. It is recommended that research be performed using actual traffic data to support this hypothesis.

\subsection{Percentage of Trucks in the Traffic Stream}

Truck volumes vary significantly by time of day and day of week as illustrated by Figures 2.1 and 2.2. Because three of the four factors of interest to this study deal directly with the travel patterns of large trucks, the variation of truck travel with respect to time is important when developing these factors. Figure 2.1 shows that the hours of peak passenger car travel differ slightly from the hours of peak truck travel. Figure 2.2 provides insight into how travel patterns vary from weekday to weekend. These figures were used in developing an understanding of how passenger car and truck volumes vary with hour of the day. 


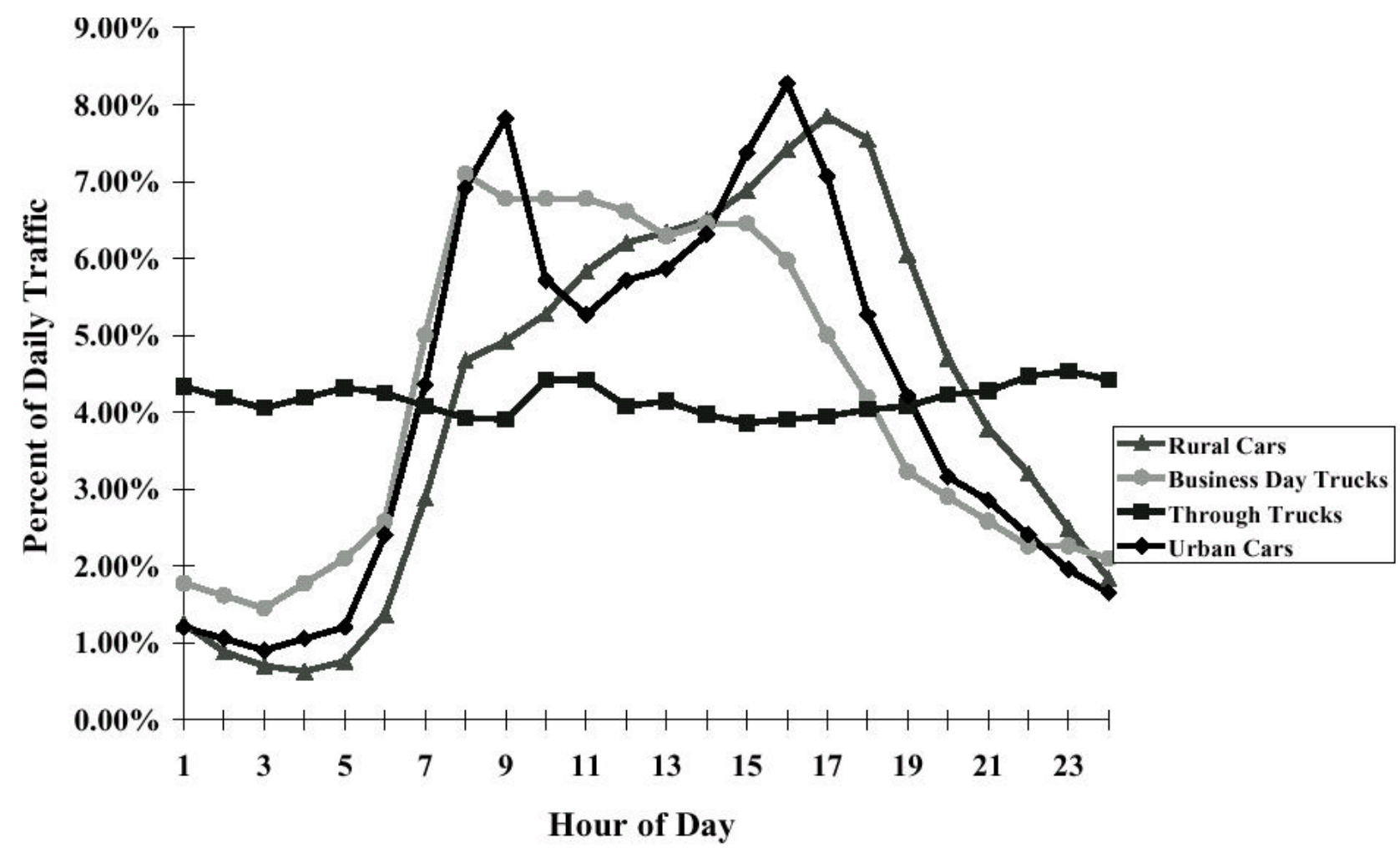

Figure 2.1: Basic Time of Day Patterns in Traffic Volume (FHWA, 2001) 


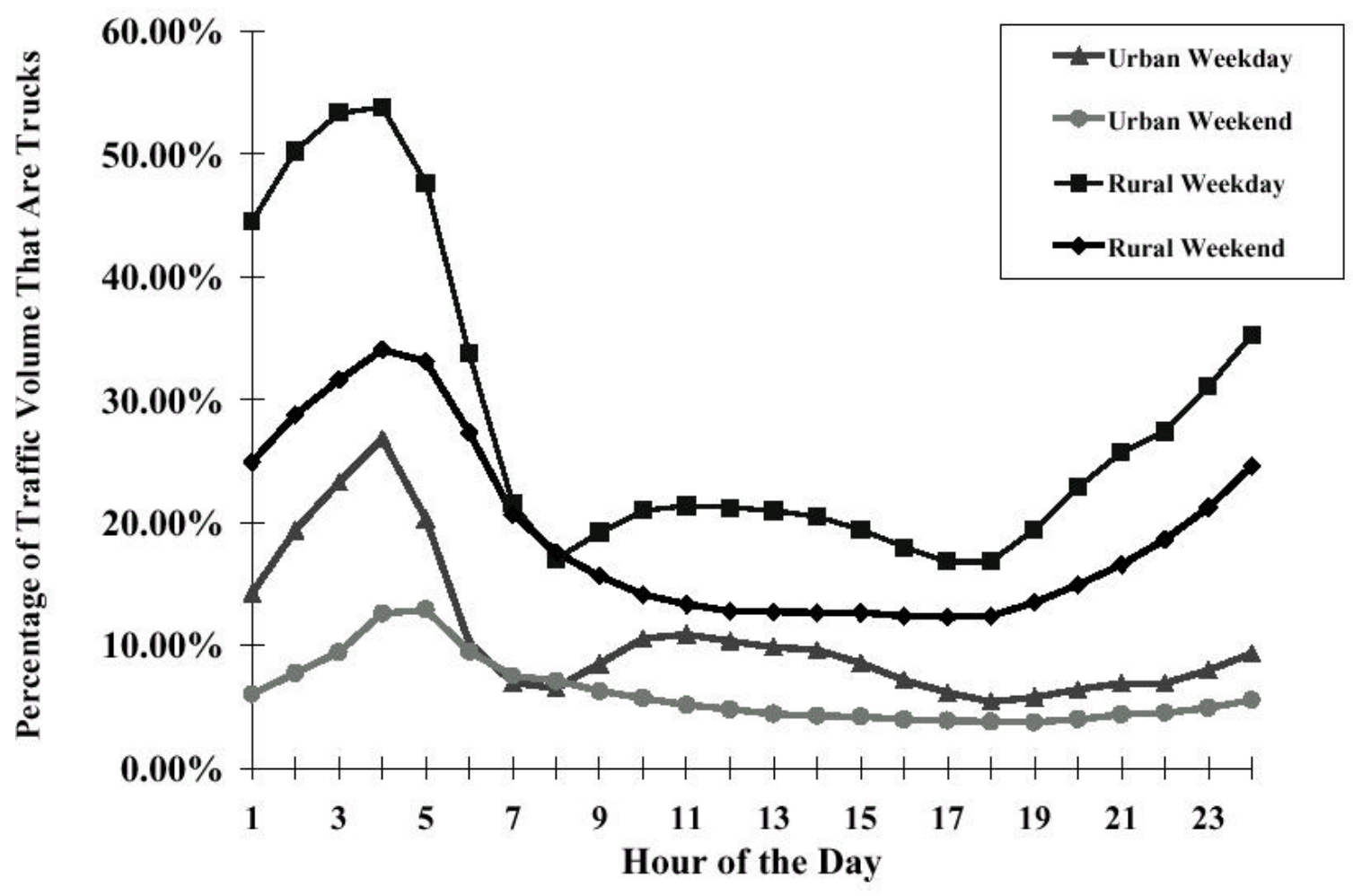

Figure 2.2: Typical Hour of the Day Travel Patterns for Large Trucks (FHWA, 2001)

The methodology behind calculating the percent trucks in the traffic stream can be understood by reading the following excerpt from the Traffic Monitoring Guide (FHWA, 2001):

"Because the volumes of cars and trucks often are very different, the effect of these different time-of-day patterns on summary statistics such as "percent trucks" and "total volume" can be unexpected. Often, in daylight hours, car volumes are so high in comparison to truck volumes that the car travel pattern dominates, and 
the percentage of trucks is very low. However, at night on that same roadway, car volumes may decrease significantly while through-truck movements continue, so that the truck percentage increases considerably, and the total volume declines less than the car pattern would predict. Because these changes can be so significant, it is important to account for them in the design and execution of the traffic monitoring program, as well as in the computation and reporting of summary statistics."

Estimating the percentage of trucks in the average daily traffic can be accomplished by developing a factor which relates the percent trucks in the ADT to 1) the percent trucks in the peak hour, or 2) the percent trucks in the manual count hours. The first factor allows traffic engineers and roadway designers to determine the percentage of trucks using the roadway on a daily basis based on the percentage of trucks in the traffic stream during the peak hour. The second factor relates the percentage of trucks in the ADT to the percentage of trucks in the manual count hours used by the WVDOT, which are: 7am10am, 11am-1pm, and 2pm-6pm. These hours are used by the WVDOT to ensure that the morning, noon, and evening peak hours were counted. The West Virginia Department of Transportation performs manual classification counts Monday through Thursday. Because trucks do not follow the same travel pattern as passenger cars, a factor must be applied to the percentage of trucks found during the manual classification count hours so that an accurate estimate of the percentage of trucks can be determined from a short-term count. 


\subsection{Relationship of Design Hour Volume and Peak Hour Volume}

The design hour volume is defined by both AASHTO (1992) and FHWA (2001) as the hourly traffic volume, usually represented by the thirtieth highest hourly volume of the future year, chosen for design. The peak hour volume is the greatest hourly volume of traffic counted during one day's time. Using permanent traffic counters, the traffic volumes for every day of the year can be calculated, sorted based on total volume, and plotted on a graph from the highest volume experienced to lowest. The design hourly volume is then chosen based on where the plotted curve levels out. Use of the design hourly volume ensures that the roadway is not designed based on unreasonably high traffic volumes that occurred during special incidents such as football games or holidays. It is recommended by both AASHTO (1992) and FHWA (2001) that the hour chosen lies between the $10^{\text {th }}$ and $50^{\text {th }}$ highest hourly volumes for the year. The factor derived based on the permanent count stations should then be applied to temporary counts so that the DHV of a roadway can be estimated with the peak-hour count found during a 48-hour count. The DHV of a roadway is greater than the PHV for most days if the short-term count day is selected so that special incidents are avoided.

\subsection{Other States' Programs}

As noted earlier, both PENNDOT and the Michigan DOT documents were examined. Both agencies published findings from their traffic monitoring programs. It was apparent that PENNDOT (Bureau of Planning and Research, 1989) and Michigan DOT 
(Bureau of Transportation Planning, 2000) both used the TMG and AASHTO recommended process of developing axle correction factors. Both began with raw count data collected at permanent count stations located throughout the state. These count stations were then grouped into statistically similar groups based on functional class or geography. The factors developed from the permanent count stations were then applied to short-term counts performed with axle counters such as pneumatic tubes.

The traffic pattern groupings (TPG) used by PENNDOT and the axle correction factors are shown in Table 2.5. Functional classification, geography, and urban/rural characteristics were used to group the locations.

Table 2.5 - PENNDOT'S Traffic Pattern Groupings

\begin{tabular}{|l|l|l|}
\hline TPG 1 & Urban & Interstate \\
\hline TPG 2 & Rural & Interstate \\
\hline TPG 3 & Urban & Other Principal Arterials \\
\hline TPG 4 & Rural & Other Principal Arterials \\
\hline TPG 5 & Urban & Minor Arterials, Collectors, Local Roads \\
\hline TPG 6 & North Rural & Minor Arterials \\
\hline TPG 7 & Central Rural & Minor Arterials \\
\hline TPG 8 & North Rural & Collectors and Local Roads \\
\hline TPG 9 & Central Rural & Collectors and Local Roads \\
\hline TPG 10 & Special Recreational & \\
\hline
\end{tabular}

The axle correction factors developed in the PENNDOT study will be used to draw a comparison with the current WVDOH study. The factors reported by PENNDOT for the ten traffic pattern groups are shown in Table 2.6. 
Table 2.6 - Axle Correction Factors Reported by PENNDOT

\begin{tabular}{|c|c|}
\hline TPG & Correction Factor \\
\hline \hline 1 & 0.840 \\
\hline 2 & 0.702 \\
\hline 3 & 0.941 \\
\hline 4 & 0.897 \\
\hline 5 & 0.980 \\
\hline 6 & 0.935 \\
\hline 7 & 0.950 \\
\hline 8 & 0.966 \\
\hline 9 & 0.97 \\
\hline 10 & 0.968 \\
\hline
\end{tabular}

The Michigan DOT document was their procedures manual. The manual did not report any specific factors, but provided a list of the traffic pattern groups used when developing factors. The traffic pattern groups were derived based not on functional classification; rather they were grouped based on urban/rural characteristics, geography, and recreational uses. The groupings used by Michigan DOT are shown in Table 2.7.

Table 2.7 - Michigan DOT's Traffic Pattern Groupings

\begin{tabular}{|c|c|}
\hline Pattern & Description \\
\hline \hline & Urban/Rural \\
\hline 2 & Rural \\
\hline 3 & Urban \\
\hline 4 & Recreational \\
\hline 5 & Straits Area Recreational \\
\hline 6 & Rural/Recreational \\
\hline 7 & Urban Area Limit \\
\hline
\end{tabular}




\subsection{Concluding Remarks}

In summary, both the Traffic Monitoring Guide (FHWA, 2001) and the $\underline{\text { AASHTO }}$ Guidelines for Traffic Data Programs (1992) emphasize the need for an axle adjustment factor. Once the data are collected for the thirteen FHWA vehicle classifications, both documents recommended grouping the sites by similar characteristics such as functional class, geography within the state, urban/rural characteristics, and seasonality (recreational). Testing how well the permanent traffic counters fit into the grouped categories can be performed by using graphical analysis or cluster analysis. Once the groups are finalized, each traffic counter in the state can then be placed into one of the groups. This will give each counter a factor for every day of the year that will convert the axle count into a more useful traffic count based on the time-of-day, day-of-week, and seasonal travel pattern.

In 1975, the WVDOH developed axle correction factors, factors for estimating DHV by using the PHV, and factors used for estimating the \% Trucks in the ADT by using the \% Trucks in the PHV. These factors are over 25 years old. Since their development, the demographics of the state, travel patterns, and commercial vehicle operations have changed. Thus, these factors need to be updated to provide the West Virginia Division of Highways with valid current factors. 


\section{Chapter 3}

METHODOLOGY

\subsection{Data Acquisition}

The data for this project was provided by the Traffic Analysis Section of Planning and Research Division of the West Virginia Department of Transportation for the 52 permanent count stations located throughout the state. The raw data was from counts performed for the years 1995 and 1996, the most recent data the WVDOT had gathered from the permanent count stations. Traffic volumes and classification data were recorded every hour of the year for every lane at every station. Vehicles were classified into one of the thirteen FHWA vehicle classification categories. Functional classes considered were consistent with the Traffic Monitoring Guide (FHWA, 2001). The number of sites in each functional class as well as the descriptions of each functional class are shown in Table 3.1.

Table 3.1 - Number of Sites in Each Functional Class

\begin{tabular}{|c|c|c|c|}
\hline $\begin{array}{c}\text { Functional } \\
\text { Classification }\end{array}$ & $\begin{array}{c}\text { Functional Class } \\
\text { Description }\end{array}$ & $\begin{array}{c}\text { Number of Sites } \\
\mathbf{1 9 9 5}\end{array}$ & $\begin{array}{c}\text { Number of Sites } \\
\mathbf{1 9 9 6}\end{array}$ \\
\hline \hline & Rural interstate & & \\
1 & Rural principal arterial - other & 4 & 7 \\
2 & Rural minor arterial & 10 & 8 \\
6 & Rural major collector & 11 & 11 \\
7 & Urban interstate & 5 & 5 \\
11 & Urban principal arterial - other freeways & 2 & 2 \\
12 & Urban other principal arterial & 5 & 5 \\
14 & Urban minor arterial & 3 & 3 \\
16 & Urban collector & 1 & 1 \\
17 & Total Sites & 48 & 46 \\
\hline \multicolumn{2}{|r|}{}
\end{tabular}


Note that the numbers vary from 1995 to 1996 and add up to less than 52 count stations because some sites were not included in the raw data and others had many data errors and, therefore, had to be discarded. Of the 104 total count stations $(52 * 2=104)$ used between both 1995 and 1996, 9 sites were missing all of their data. These sites included four from functional class 1 , one from functional class 2 , two came from functional class 6 , and two were missing from functional class 11.

The raw data files consisted of one file for every day of the year. The files from each site for a given year needed to be collapsed into one large file. The program "Reporter" was provided by the WVDOT and was used to perform the conversion of the data files from their collected format into a Microsoft Excel format. Once "Reporter" was implemented, the 365 Excel files had to be organized into one large file so that further analysis could take place. The following workbooks were created for each site in an effort to further organize the data: "by lane", "by direction", "by hour", "by day", and "by month."

The next step was to determine and identify the types of errors contained in the raw data files and eliminate the errors so the results would be accurate. The errors were detected primarily manually at the database organization stage, but also when the factors were computed (because they had a significant impact of the factors). Types of errors identified included the following: 1) missing data, 2) unreasonably large numbers, 3) functional classes switched (functional classes 1 and 2), and 4) zeros. Errors ranged from $81 \%$ of the days containing errors to $4 \%$ of the days in error. Overall, the data for 1996 , averaging $28 \%$ of the days containing errors per site, contained more erroneous data than 
1995 which averaged $25 \%$ of the days in error per site. These figures are skewed slightly because several sites were completely removed from 1996 because they contained so many errors, or no data at all, thus they were not included in the raw data sent by the WVDOT. By recommendation of the AASHTO Guidelines for Traffic Data Programs (1992) and the Traffic Monitoring Guide (FHWA, 2001), data in error were omitted from further analysis, and no data containing errors was corrected and used in the formulation of any factors. The data was then analyzed in accordance with the Traffic Monitoring Guide (FHWA, 2001) and the AASHTO Guidelines (1992).

The factors of interest were:

1) An axle correction factor that could be applied to short-term single pneumatic tube axle counts to counteract the effect of 3 or more axle trucks on vehicle counts.

2) A method of estimating the design hour volume by developing a peak hour volume to design hour volume factor.

3) Determine a factor relating the Percent Trucks in the ADT to Percent Trucks in the Peak Hour.

4) Determine a factor relating the Percent Trucks in the ADT to Percent Trucks in the Manual Count hours.

The factors were developed using the 1995 data, and then again using the data from 1996. By request of the WVDOT, the factors developed using the 1996 database were used to validate the procedure used to determine the 1995 factors. Previously overlooked errors 
were discovered when the 19965 and 1996 factors were plotted and compared. These errors were located and removed.

\subsection{Axle Correction Factor Procedure}

The process of developing the axle correction factors began by assigning the 13 FHWA vehicle classes a number of axles as recommended by the TMG (FHWA, 2001) and previously shown in Table 2.1. The actual number of vehicles was known by tabulating the vehicles in the thirteen vehicle classifications counted by the permanent count station. The number of vehicles that would have been reported by the pneumatic tube counter would be the total number of axles divided by two. The following equation demonstrates how the factor was developed. The actual number of vehicles that traveled over the pneumatic tube count station can be determined by multiplying the number of vehicles determined by the short-term pneumatic tube counter by the axle correction factor.

Axle correction factor $=$ actual number of vehicles \# of vehicles reported by pneumatic tube counter

where:

$\#$ of vehicles reported by pneumatic tube counter $=\frac{\text { total \# of axles }}{2}$

It should be noted that the raw data file provided by the WVDOH included 15 vehicle classifications. This fact was brought to the attention of the WVDOH project monitor. The response was that classifications 1 through 13 are the FWHA classes, and 14 and 15 are columns in which vehicle are categorized when the traffic counter did not categorize 
the vehicle. These columns were simply disregarded and not included in the factor development.

The average numbers of axles per vehicle class were then applied to the "by day" summaries. Columns calculated included number of axles, short-term raw count, real count, and real / raw. The real divided by raw is the axle correction factor for that day. The axle correction factors were then developed for the day of the year regardless of month, by month, and by quarter.

The next step was to establish a method of grouping the factors for the 52 sites in a statistically significant manner. The TMG (FHWA, 2001) states that rural interstates and urban interstates, functional classes 1 and 11, respectively, should both stand alone as groupings. Grouping, according to the TMG, should then be made based on functional classification, geography, or other characteristics that would allow the sites to be grouped in a statistically significant manner. Grouping by functional class, which included the aggregation of different functional classes in a few was the method utilized in this project.

As in the 1975 study, single-factor analysis of variance, (ANOVA) was also used to perform the statistical analysis throughout the project. Single-factor ANOVA involves the analysis either of data sampled from more than two numerical populations or data from an experiment in which more than two treatments have been used. Single-factor ANOVA focuses on a comparison of more than two populations. In the case of this project, the means were compared by day of the week, by month, and by quarter. 
ANOVA analysis of the functional class groupings based on the aforementioned time increments would then indicate whether there was a statistically significant difference in the groupings. Table 3.2 was constructed to aid in analysis of the groupings. Functional classification 12 was not originally included in the groupings because it consisted of only two sites, one of which contained many (81\%) erroneous days. This would not permit functional class 12 to be sufficiently analyzed by ANOVA analysis. Functional class 12 was eventually grouped with class 14 .

Table 3.2 shows that the most significant difference occurs when the axle correction factors are grouped by day regardless of the month of the year. With the other groupings, there were generally no significant differences.

Table 3.2 - Preliminary ANOVA Analysis for the Axle Correction Factor

\begin{tabular}{|c|c|c|c|}
\hline Grouping Procedure & Functional Class Groupings & 1995 & 1996 \\
\hline by month & $\begin{array}{c}1 \\
2 \\
6,7 \\
11 \\
14,16,17\end{array}$ & $\begin{array}{c}\text { different } \\
\text { not different } \\
\text { not different } \\
\text { not different } \\
\text { not different }\end{array}$ & $\begin{array}{l}\text { not different } \\
\text { not different } \\
\text { not different } \\
\text { not different } \\
\text { not different }\end{array}$ \\
\hline by quarter - weighted & $\begin{array}{c}1 \\
2 \\
6,7 \\
11 \\
14,16,17\end{array}$ & $\begin{array}{c}\text { different } \\
\text { not different } \\
\text { not different } \\
\text { not different } \\
\text { not different }\end{array}$ & $\begin{array}{l}\text { not different } \\
\text { not different } \\
\text { not different } \\
\text { not different } \\
\text { not different }\end{array}$ \\
\hline by day regardless of month & $\begin{array}{c}1 \\
2 \\
6,7 \\
11 \\
14,16,17 \\
\end{array}$ & $\begin{array}{c}\text { different } \\
\text { different } \\
\text { not different } \\
\text { different } \\
\text { not different }\end{array}$ & \begin{tabular}{|c|} 
different \\
different \\
not different \\
not different \\
not different
\end{tabular} \\
\hline
\end{tabular}


Table 3.3 provides a summary of the ANOVA analysis on the functional classification groupings with all Fridays, Saturdays, and Sundays removed. The WVDOH suggested that the factors be developed without Friday, Saturday, and Sunday due to the fact that manual and short-term counts are not performed on these days and also due to the fact that these days have the greatest variability. Note that there is virtually no significant difference in the axle correction factors when grouped by functional class, no matter which time increment grouping is used. Therefore, data for Friday, Saturday, and Sunday was not used in the development of any of the factors in this study. Factors for only Friday, Saturday, and Sunday were developed and are included in Appendix E for informational purposes.

Table 3.3 - ANOVA Analysis Summary for Axle Correction Factor with Friday, Saturday, and Sunday Removed

\begin{tabular}{|c|c|c|c|}
\hline Grouping Procedure & Functional Class Groupings & 1995 & 1996 \\
\hline by month & $\begin{array}{c}1 \\
2 \\
6,7 \\
11 \\
14,16,17\end{array}$ & $\begin{array}{c}\text { different } \\
\text { not different } \\
\text { not different } \\
\text { not different } \\
\text { not different }\end{array}$ & $\begin{array}{l}\text { not different } \\
\text { not different } \\
\text { not different } \\
\text { not different } \\
\text { not different }\end{array}$ \\
\hline by quarter - weighted & $\begin{array}{c}1 \\
2 \\
6,7 \\
11 \\
14,16,17\end{array}$ & $\begin{array}{l}\text { not different } \\
\text { not different } \\
\text { not different } \\
\text { not different } \\
\text { not different }\end{array}$ & $\begin{array}{l}\text { not different } \\
\text { not different } \\
\text { not different } \\
\text { not different } \\
\text { not different }\end{array}$ \\
\hline by day regardless of month & $\begin{array}{c}1 \\
2 \\
6,7 \\
11 \\
14,16,17\end{array}$ & $\begin{array}{l}\text { not different } \\
\text { not different } \\
\text { not different } \\
\text { not different } \\
\text { not different }\end{array}$ & $\begin{array}{l}\text { not different } \\
\text { not different } \\
\text { not different } \\
\text { not different } \\
\text { not different }\end{array}$ \\
\hline
\end{tabular}


The decision was then made to re-evaluate some of the functional class groupings to ensure that they were grouped in the best possible manner. The functional class groupings analyzed were as follows:

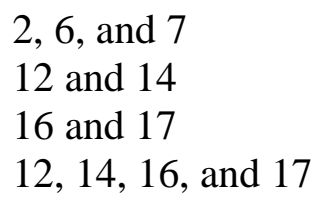

After analyzing the factors developed by such groupings, it was decided that the functional class groupings should be as follows:

$\begin{array}{lcl}\text { Group 1) } & 1 & \text { Rural interstate } \\ \text { Group 2) } & 2 & \text { Rural principal arterial }- \text { other } \\ \text { Group 3) } & 6 \text { and } 7 & \text { Rural minor arterial, Rural major collector } \\ \text { Group 4) } & 11 & \text { Urban interstate } \\ \text { Group 5) } & 12 \text { and } 14 & \text { Urban principal arterial }- \text { other freeways, } \\ & & \text { Urban other principal arterial } \\ \text { Group 6) } & 16 \text { and } 17 & \text { Urban minor arterial, Urban collector }\end{array}$

Factors were developed for these new groupings (still excluding Friday, Saturday, and Sunday) for the day of the week, by month, and by quarter. ANOVA analysis could not be performed on the new groupings, since some groups included only three sites. ANOVA was performed on the sites when they were a part of larger groupings.

\subsection{Estimating Design Hour Volume}

The following equation was used in determining the peak hour to design hour factor:

$$
\text { Design Hour Factor }=\frac{\text { Design Hour Volume }}{\text { Peak Hour Volume }}
$$


In order to correctly choose the DHV for each site, graphs of the 100-300 highest hourly volumes were made for each site.

Figure 3.1 - Example of Determination of Design Hour Volume

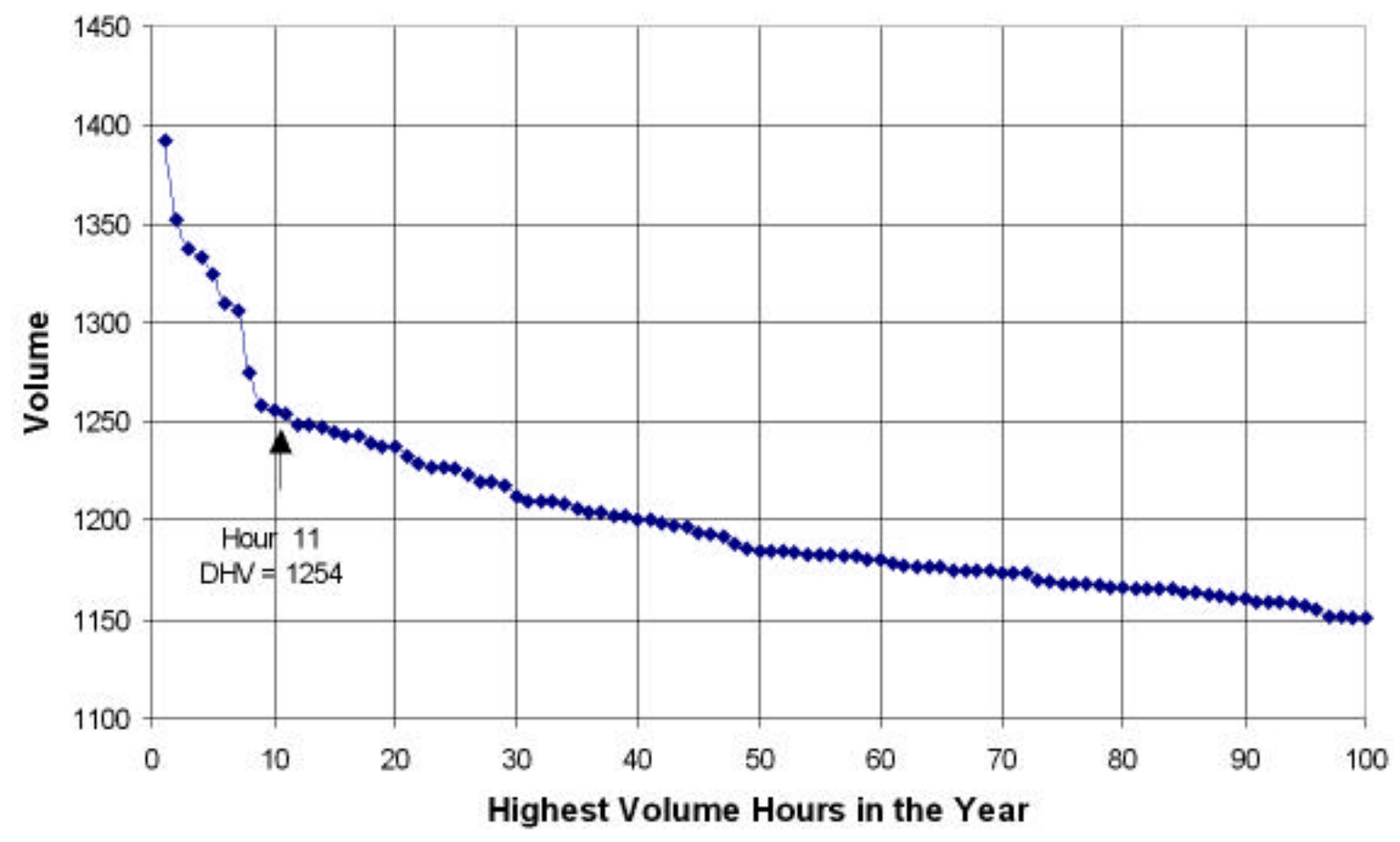

The DHV was chosen visually, based on where the curve leveled. Figure 3.1 presents an example of how the DHV volumes were chosen. The $30^{\text {th }}$ highest hourly volume usually falls around this region, thus it is used as a standard approach. But because of the missing data, rather than choosing the $30^{\text {th }}$ highest hourly volume, the DHV was chosen based on where the curve leveled out. At this point, the chosen volume would represent the majority of the highest volume hours in the year, but not include the extraordinarily high hourly volumes such as would be attributable to special events. 
The design hourly volume for each site was then divided by the peak hour volume for each day, creating the factor. The factors were then combined by day regardless of month, by month, and by quarter. The same functional class groupings identified with the axle correction factors were used. ANOVA analysis was then performed on the functional classification groupings to ensure that the same groupings would be sufficient. Table 3.4 was constructed to aid in the evaluation of the groupings. Table 3.4 shows that all grouping procedures yielded statistically significantly different values. This led to the conclusion that the day of the week by month should be used to report the factors.

Table 3.4 - Preliminary ANOVA Analysis for the PHV to DHV Factor

\begin{tabular}{|c|c|c|c|}
\hline Grouping Procedure & Functional Class Groupings & 1995 & 1996 \\
\hline by month & $\begin{array}{c}1 \\
2 \\
6,7 \\
11 \\
14,16,17\end{array}$ & $\begin{array}{c}\text { different } \\
\text { not different } \\
\text { different } \\
\text { not different } \\
\text { different }\end{array}$ & $\begin{array}{c}\text { not different } \\
\text { different } \\
\text { different } \\
\text { not different } \\
\text { not different }\end{array}$ \\
\hline by quarter - weighted & $\begin{array}{c}1 \\
2 \\
6,7 \\
11 \\
14,16,17\end{array}$ & $\begin{array}{c}\text { different } \\
\text { not different } \\
\text { different } \\
\text { not different } \\
\text { not different }\end{array}$ & $\begin{array}{c}\text { not different } \\
\text { different } \\
\text { not different } \\
\text { not different } \\
\text { not different }\end{array}$ \\
\hline by day regardless of month & $\begin{array}{c}1 \\
2 \\
6,7 \\
11 \\
14,16,17 \\
\end{array}$ & $\begin{array}{c}\text { different } \\
\text { not different } \\
\text { different } \\
\text { not different } \\
\text { different }\end{array}$ & \begin{tabular}{|c} 
not different \\
different \\
not different \\
not different \\
not different \\
\end{tabular} \\
\hline
\end{tabular}


For the reasons previously cited, the groupings were re-evaluated with Friday, Saturday, and Sunday removed from the database. Table 3.5 shows the results of the ANOVA analysis performed.

Table 3.5 - ANOVA Analysis Summary for PHV to DHV Factor with Friday, Saturday, and Sunday Removed

\begin{tabular}{|c|c|c|c|}
\hline Grouping Procedure & Functional Class Groupings & 1995 & 1996 \\
\hline by month & $\begin{array}{c}1 \\
2 \\
6,7 \\
11 \\
14,16,17\end{array}$ & $\begin{array}{l}\text { not different } \\
\text { not different } \\
\text { not different } \\
\text { not different } \\
\text { not different }\end{array}$ & $\begin{array}{l}\text { not different } \\
\text { not different } \\
\text { not different } \\
\text { not different } \\
\text { not different }\end{array}$ \\
\hline by quarter - weighted & $\begin{array}{c}1 \\
2 \\
6,7 \\
11 \\
14,16,17\end{array}$ & $\begin{array}{l}\text { not different } \\
\text { not different } \\
\text { not different } \\
\text { not different } \\
\text { not different }\end{array}$ & $\begin{array}{l}\text { not different } \\
\text { not different } \\
\text { not different } \\
\text { not different } \\
\text { not different }\end{array}$ \\
\hline by day regardless of month & $\begin{array}{c}1 \\
2 \\
6,7 \\
11 \\
14,16,17 \\
\end{array}$ & $\begin{array}{l}\text { not different } \\
\text { not different } \\
\text { not different } \\
\text { not different } \\
\text { not different }\end{array}$ & $\begin{array}{l}\text { not different } \\
\text { not different } \\
\text { not different } \\
\text { not different } \\
\text { not different }\end{array}$ \\
\hline
\end{tabular}

The decision was then made to re-evaluate the functional class groupings to ensure that they were grouped in the best possible way. The same conclusion was reached as before in the axle correction factor. The functional class groupings were as follows:

$\begin{array}{lcl}\text { Group 1) } & 1 & \text { Rural interstate } \\ \text { Group 2) } & 2 & \text { Rural principal arterial }- \text { other } \\ \text { Group 3) } & 6 \text { and } 7 & \text { Rural minor arterial, Rural major collector } \\ \text { Group 4) } & 11 & \text { Urban interstate } \\ \text { Group 5) } & 12 \text { and } 14 & \begin{array}{l}\text { Urban principal arterial }- \text { other freeways, } \\ \text { Urban other principal arterial }\end{array} \\ \text { Group 6) } & 16 \text { and } 17 & \text { Urban minor arterial, Urban collector }\end{array}$


Because high AADT facilities may have more uniform peaking characteristics due to capacity constraints, AADT was used to further stratify the sites. The AADT was determined by averaging the daily volumes for an entire year. A yearly factor was calculated for each site by taking the average of the day of the month factors. This led to 48 factors being averaged together ( 4 days in the week multiplied by 12 months of the year). The functional classification groupings were then sorted based on their AADT and the factors were analyzed. Table 3.6 shows the relationship between the AADT and the PHV to DHV factor. The results of this analysis were that 1) a breakpoint in functional class 1 occurred at 30,000 vehicles in the AADT, thus two different factors would be developed for this group, and 2) a breakpoint occurred in the grouping of functional classifications 6 and 7 around 5,000 vehicles in the AADT. Separate factors would be developed for this grouping based on this AADT relationship.

Due to the reporting of the factors in such an expanded manner, the missing and flawed data caused by machine malfunctions created difficulties in performing an ANOVA analysis on the data. This caused many statistical problems. For example, a functional class that contains eight sites may only have two sites that contain a value for Tuesday in November.

\subsection{Relationship of \% Trucks in the ADT to \% Trucks in the Peak Hours}

At each station for each day, the peak hour was selected and the percentage of trucks was determined. The percentage of trucks for the entire day was also determined. The factor was calculated as follows:

$$
\text { factor }=\frac{\% \text { trucks in ADT }}{\% \text { trucks in PHV }}
$$


Table 3.6 - Relationship of AADT and PHV-DHV Factor

\begin{tabular}{|c|c|c|c|c|}
\hline $\begin{array}{c}\begin{array}{c}\text { Functional } \\
\text { Class }\end{array} \\
\end{array}$ & Site & $\begin{array}{l}\text { Percent } \\
\text { in Err }\end{array}$ & $\overline{\text { AADT }}$ & $\begin{array}{l}\text { PHV to DHV } \\
\text { Factor }\end{array}$ \\
\hline 1 & $\overline{50}$ & $\overline{43 \%}$ & 445500 & $\overline{1.20}$ \\
\hline 1 & 39 & $20 \%$ & 34500 & 1.38 \\
\hline 1 & 3 & $38 \%$ & 29000 & 1.87 \\
\hline 1 & 47 & $28 \%$ & 23500 & 1.86 \\
\hline 1 & 5 & $9 \%$ & 18000 & 1.67 \\
\hline 1 & 53 & $10 \%$ & 16000 & 1.99 \\
\hline 1 & 1 & $5 \%$ & 11500 & 2.00 \\
\hline 2 & 11 & $44 \%$ & 12300 & 1.30 \\
\hline 2 & 9 & $28 \%$ & 11400 & 1.27 \\
\hline 2 & 10 & $8 \%$ & 5000 & 1.25 \\
\hline 2 & 7 & $10 \%$ & 3700 & 1.20 \\
\hline 6 & 13 & $9 \%$ & 14000 & 1.11 \\
\hline 6 & 14 & $45 \%$ & 12600 & 1.26 \\
\hline 7 & 43 & $35 \%$ & 12400 & 1.08 \\
\hline 7 & 25 & $15 \%$ & 7800 & 1.27 \\
\hline 6 & 17 & $19 \%$ & 7100 & 1.09 \\
\hline 6 & 16 & $18 \%$ & 6900 & 1.26 \\
\hline 7 & 23 & $25 \%$ & 6700 & 1.12 \\
\hline 6 & 15 & $15 \%$ & 6100 & 1.44 \\
\hline 6 & 44 & $48 \%$ & 5900 & 1.13 \\
\hline 6 & 48 & $38 \%$ & 5900 & 1.16 \\
\hline 7 & 51 & $24 \%$ & 5300 & 1.16 \\
\hline 7 & 45 & $28 \%$ & 5100 & 1.34 \\
\hline 7 & 24 & $15 \%$ & 4100 & 1.20 \\
\hline 6 & 12 & $42 \%$ & 2900 & 1.19 \\
\hline 7 & 22 & $25 \%$ & 2600 & 1.28 \\
\hline 7 & 21 & $14 \%$ & 2300 & 2.11 \\
\hline 7 & 19 & $18 \%$ & 2000 & 1.18 \\
\hline 6 & 18 & $20 \%$ & 1800 & 1.25 \\
\hline 7 & 20 & $42 \%$ & 1500 & 1.30 \\
\hline 7 & 46 & $34 \%$ & 1400 & 1.67 \\
\hline 6 & 49 & $24 \%$ & 800 & 1.90 \\
\hline 11 & 27 & $47 \%$ & 63000 & 1.14 \\
\hline 11 & 42 & $33 \%$ & 43000 & 1.27 \\
\hline 11 & 30 & $9 \%$ & 42500 & 1.94 \\
\hline 11 & 2 & $6 \%$ & 36500 & 1.19 \\
\hline 11 & 26 & $15 \%$ & 28500 & 1.30 \\
\hline 14 & $351-352$ & $23 \%$ & 20800 & 1.22 \\
\hline 14 & $401-402$ & $51 \%$ & 20000 & 1.64 \\
\hline 14 & 34 & $9 \%$ & 14200 & 1.19 \\
\hline 12 & 31 & $24 \%$ & 11700 & 1.24 \\
\hline 12 & 32 & $81 \%$ & 11200 & 1.24 \\
\hline 14 & 33 & $30 \%$ & 8500 & 1.07 \\
\hline 14 & 36 & $16 \%$ & 8400 & 1.11 \\
\hline 16 & 37 & $22 \%$ & 12700 & 1.15 \\
\hline 16 & 40 & $15 \%$ & 11100 & 1.18 \\
\hline 17 & 38 & $11 \%$ & 8100 & 1.19 \\
\hline 16 & 41 & $16 \%$ & 5100 & 1.12 \\
\hline
\end{tabular}


In reviewing the original cut of factors, the factors for all but the known heavy truck routes were near 1.1. This was brought to the attention of the WVDOT and it was decided to develop a factor for heavy truck routes, and for other routes to assume a factor of 1.1. Factors were rounded to the nearest 0.1 because this is the minimum needed to change $10 \%$ trucks by $1 \%(10 \% * 1.1=11 \%)$. The permanent count sites were grouped together by 1) Urban heavy truck routes, 2) Rural heavy truck routes, and 3) Others. These groupings were developed by the staff of the Planning and Research Division of the WVDOT. Factors were then developed and analyzed for the groupings by day of the year, by day of the month, by month, and by quarter. The groupings became as follows:

Urban Heavy Truck Routes: Functional class 1

Rural Heavy Truck Routes: Functional class 11 and site 15 in functional class 6 Others: All other sites

\subsection{Relationship of \% Trucks in the ADT to \% Trucks in the Manual Count Hours}

The percentage of trucks in the manual classification study hours was compared to the percentage of trucks for the entire day. The hours used in the manual classification studies were:

$$
\begin{aligned}
& 7 \mathrm{am}-10 \mathrm{am} \\
& 11 \mathrm{am}-1 \mathrm{pm} \\
& 2 \mathrm{pm}-6 \mathrm{pm}
\end{aligned}
$$

The derivation of the factor can be seen in the following equation:

$$
\text { factor }=\frac{\% \text { trucks in ADT }}{\% \text { trucks in manual count hours }} .
$$


As with the previous \% truck factors, a first cut revealed that all but the heavy truck routes had factors near 1.0. Therefore, the factors were developed for the heavy truck routes listed in section 3.4, with non-heavy truck routes having a factor of 1.0. As with the previous $\%$ truck factors, these factors were also rounded to the nearest 0.1 . 


\section{Chapter 4}

\section{RESULTS}

\subsection{Axle Correction Factor}

After grouping the functional classes and determining the most significant temporal grouping, the axle correction factors were developed. The resulting axle correction factors are reported in Table 4.1. Functional class 1 was the only grouping in which the factor changed significantly at some point in the year. For this reason, a factor was reported for the first quarter, and another factor for the rest of the year. The other functional classification groupings could be adequately reported with one factor for the entire year. Axle correction factors developed by day of the week in each month, by month, and by quarter are presented in Appendix A for informational purposes.

\section{Table 4.1 - Axle Correction Factor Results}

\begin{tabular}{|c|c|c|c|}
\hline Functional Class & Quarter 1 & Rest of Year & Entire Year \\
\hline \hline & & & \\
1 & 0.74 & 0.80 & \\
2 & & & 0.92 \\
6,7 & & & 0.94 \\
11 & & & 0.83 \\
12,14 & & & 0.96 \\
16,17 & & & 0.99 \\
\hline
\end{tabular}

The following is an example of how these factors would be applied to a short-term pneumatic tube axle count to compute the actual traffic volume. For example, a shortterm counter located on an urban interstate (functional class 11) recorded a traffic volume of 10,000 vehicles. The factor for urban interstates would be applied, yielding the following result: 


$$
10,000 \text { vehicles } * 0.83=8,300 \text { actual number of vehicles }
$$

The factors derived by the 1975 WVDOH study were:

$\begin{array}{ll}0.92972 & \text { for feeders and local roads } \\ 0.88589 & \text { for expressways and trunklines }\end{array}$

The factors for the current study were not grouped in the same manner, i.e., were developed for six different roadway classification groups. Aggregating the numbers derived for the different functional class groupings in the current study for the purpose of drawing a comparison with the 1975 results yields the following values:

0.965 for collectors and locals

0.874 for interstates and other arterials

The values determined by both studies are similar in that the factor for interstates are lower than that of other roadway classifications because these roadways experience a higher amount of truck travel. A slight difference lies in the range between values for the different roadway classifications. In 1975 (Traffic Analysis Section, May 1975), the difference was $0.04383(0.92972-0.88589)$, while for 1995-1996 data, the same values differed by a value of 0.091 . Overall, the factor derived for both roadways groupings tended to remain stable over time.

Data from current research (Bureau of Planning and Research, 2001) by the Pennsylvania Department of Transportation concerning axle correction factors was available for comparison. Table 4.2 presents a comparison of the values derived in this project to axle 
correction factors derived by PENNDOT for the year 2000. PENNDOT used data from collected from the year 2000 while the West Virginia results are from data collected for years 1995 and 1996. The values for the axle correction factors are very similar with the largest disparity being the $8 \%$ difference in the factor used for rural interstates.

Table 4.2 - West Virginia and Pennsylvania Axle Correction Factors

\begin{tabular}{|l|c|c|}
\hline \multicolumn{1}{|c|}{ Description } & West Virginia & PENNDOT \\
\hline \hline Rural interstate & 0.78 & 0.70 \\
\hline Rural principal arterial -other & 0.92 & 0.90 \\
\hline Rural minor arterial & 0.94 & 0.94 \\
\hline Rural major collector & 0.94 & 0.97 \\
\hline Urban interstate & 0.83 & 0.84 \\
\hline Urban principal arterial -other freeways & 0.96 & 0.94 \\
\hline Urban other principal arterial & 0.96 & 0.94 \\
\hline Urban minor arterial & 0.99 & 0.98 \\
\hline Urban collector & 0.99 & 0.98 \\
\hline
\end{tabular}

\subsection{Peak Hour Volume to Design Hour Volume Factor}

The peak hour to design hour volume factors developed are reported by day of the week by month in Table 4.3. The factors developed by day of the year, by month, and by quarter are reported in Appendix B for informational purposes. The values for functional classifications 1 and the 6-7 grouping were split based on AADT, with functional class 1 being split at 30,000 vehicles and functional class grouping 6-7 being divided at a value of 5,000 vehicles. These divisions were made due to a significant variability in the PHV to DHV factors developed on the roadways with these values of AADT. 
Table 4.3 - DHV Summary by Day of the Month

\begin{tabular}{|c|c|c|c|c|c|c|c|c|c|c|c|c|c|}
\hline $\begin{array}{c}\text { Functional } \\
\text { Class }\end{array}$ & AADT Split & $\begin{array}{c}\text { January } \\
2 \\
\text { Monday } \\
\end{array}$ & $\begin{array}{c}3 \\
\text { Tuesday } \\
\end{array}$ & $\begin{array}{c}4 \\
\text { Wednesday } \\
\end{array}$ & $\begin{array}{c}5 \\
\text { Thursday } \\
\end{array}$ & $\begin{array}{c}\text { February } \\
2 \\
\text { Monday } \\
\end{array}$ & $\begin{array}{c}3 \\
\text { Tuesday } \\
\end{array}$ & $\begin{array}{c}4 \\
\text { Wednesday } \\
\end{array}$ & $\begin{array}{c}5 \\
\text { Thursday } \\
\end{array}$ & $\begin{array}{c}\text { March } \\
2 \\
\text { Monday } \\
\end{array}$ & $\begin{array}{c}3 \\
\text { Tuesday } \\
\end{array}$ & $\begin{array}{c}4 \\
\text { Wednesday } \\
\end{array}$ & $\begin{array}{c}5 \\
\text { Thursday } \\
\end{array}$ \\
\hline 1 & greater than 30,000 & 1.35 & 1.28 & 1.23 & 1.21 & 1.37 & 1.31 & 1.38 & 1.25 & 1.28 & 1.27 & 1.28 & 1.21 \\
\hline 1 & less than 30,000 & 2.18 & 2.20 & 2.21 & 2.08 & 2.18 & 2.25 & 2.27 & 2.09 & 1.91 & 1.94 & 1.99 & 1.78 \\
\hline 2 & & 1.47 & 1.35 & 1.38 & 1.31 & 1.42 & 1.35 & 1.46 & 1.31 & 1.25 & 1.25 & 1.31 & 1.20 \\
\hline 6 and 7 & greater than 5,000 & 1.43 & 1.24 & 1.27 & 1.19 & 1.26 & 1.24 & 1.31 & 1.23 & 1.25 & 1.22 & 1.19 & 1.13 \\
\hline 6 and 7 & less than 5,000 & 1.64 & 1.60 & 1.53 & 1.39 & 1.73 & 1.73 & 1.75 & 1.49 & 1.81 & 1.81 & 1.77 & 1.64 \\
\hline 11 & & 1.54 & 1.43 & 1.42 & 1.41 & 1.62 & 1.49 & 1.55 & 1.46 & 1.54 & 1.48 & 1.54 & 1.51 \\
\hline 12 and 14 & & 1.44 & 1.25 & 1.34 & 1.28 & 1.37 & 1.24 & 1.31 & 1.21 & 1.26 & 1.24 & 1.19 & 1.12 \\
\hline \multirow[t]{2}{*}{16 and 17} & & 1.35 & 1.13 & 1.15 & 1.10 & 1.21 & 1.14 & 1.32 & 1.18 & 1.07 & 1.08 & 1.22 & 1.13 \\
\hline & & April & & & & May & & & & June & & & \\
\hline $\begin{array}{c}\text { Functional } \\
\text { Class }\end{array}$ & AADT Split & $\begin{array}{c}2 \\
\text { Monday } \\
\end{array}$ & $\begin{array}{c}3 \\
\text { Tuesday } \\
\end{array}$ & $\begin{array}{c}4 \\
\text { Wednesday } \\
\end{array}$ & $\begin{array}{c}5 \\
\text { Thursday } \\
\end{array}$ & $\begin{array}{c}2 \\
\text { Monday } \\
\end{array}$ & $\begin{array}{c}3 \\
\text { Tuesday } \\
\end{array}$ & $\begin{array}{c}4 \\
\text { Wednesday } \\
\end{array}$ & $\begin{array}{c}5 \\
\text { Thursday } \\
\end{array}$ & $\begin{array}{c}2 \\
\text { Monday }\end{array}$ & $\begin{array}{c}3 \\
\text { Tuesday }\end{array}$ & $\begin{array}{c}4 \\
\text { Wednesday }\end{array}$ & $\begin{array}{c}5 \\
\text { Thursday }\end{array}$ \\
\hline 1 & greater than 30,000 & 1.24 & 1.22 & 1.21 & 1.14 & 1.19 & 1.20 & 1.17 & 1.12 & 1.17 & 1.22 & 1.17 & 1.11 \\
\hline 1 & less than 30,000 & 1.68 & 1.82 & 1.77 & 1.51 & 1.62 & 1.84 & 1.86 & 1.62 & 1.73 & 1.82 & 1.73 & 1.56 \\
\hline 2 & & 1.23 & 1.20 & 1.22 & 1.18 & 1.22 & 1.21 & 1.20 & 1.10 & 1.28 & 1.19 & 1.20 & 1.17 \\
\hline 6 and 7 & greater than 5,000 & 1.15 & 1.15 & 1.15 & 1.10 & 1.17 & 1.15 & 1.17 & 1.13 & 1.15 & 1.17 & 1.18 & 1.15 \\
\hline 6 and 7 & less than 5,000 & 1.55 & 1.54 & 1.47 & 1.40 & 1.49 & 1.48 & 1.47 & 1.46 & 1.48 & 1.38 & 1.44 & 1.37 \\
\hline 11 & & 1.39 & 1.37 & 1.37 & 1.25 & 1.40 & 1.39 & 1.50 & 1.40 & 1.29 & 1.30 & 1.26 & 1.22 \\
\hline 12 and 14 & & 1.23 & 1.18 & 1.16 & 1.11 & 1.22 & 1.16 & 1.17 & 1.11 & 1.19 & 1.17 & 1.16 & 1.12 \\
\hline \multirow[t]{2}{*}{16 and 17} & & 1.12 & 1.10 & 1.11 & 1.12 & 1.19 & 1.09 & 1.08 & 1.08 & 1.16 & 1.14 & 1.15 & 1.11 \\
\hline & & July & & & & August & & & & Septembe & & & \\
\hline $\begin{array}{c}\text { Functional } \\
\text { Class }\end{array}$ & AADT Split & $\begin{array}{c}2 \\
\text { Monday } \\
\end{array}$ & $\begin{array}{c}3 \\
\text { Tuesday } \\
\end{array}$ & $\begin{array}{c}4 \\
\text { Wednesday } \\
\end{array}$ & $\begin{array}{c}5 \\
\text { Thursday } \\
\end{array}$ & $\begin{array}{c}2 \\
\text { Monday } \\
\end{array}$ & $\begin{array}{c}3 \\
\text { Tuesday } \\
\end{array}$ & $\begin{array}{c}4 \\
\text { Wednesday } \\
\end{array}$ & $\begin{array}{c}5 \\
\text { Thursday } \\
\end{array}$ & $\begin{array}{c}2 \\
\text { Monday } \\
\end{array}$ & $\begin{array}{c}3 \\
\text { Tuesday } \\
\end{array}$ & $\begin{array}{c}4 \\
\text { Wednesday } \\
\end{array}$ & $\begin{array}{c}5 \\
\text { Thursday } \\
\end{array}$ \\
\hline 1 & greater than 30,000 & 1.16 & 1.22 & 1.16 & 1.12 & 1.14 & 1.15 & 1.14 & 1.09 & 1.15 & 1.17 & 1.16 & 1.12 \\
\hline 1 & less than 30,000 & 1.62 & 1.72 & 1.65 & 1.52 & 1.59 & 1.71 & 1.70 & 1.54 & 1.63 & 1.63 & 1.83 & 1.76 \\
\hline 2 & & 1.31 & 1.27 & 1.19 & 1.19 & 1.29 & 1.22 & 1.16 & 1.18 & 1.29 & 1.20 & 1.23 & 1.19 \\
\hline 6 and 7 & greater than 5,000 & 1.17 & 1.31 & 1.20 & 1.17 & 1.18 & 1.20 & 1.23 & 1.16 & 1.17 & 1.16 & 1.18 & 1.16 \\
\hline 6 and 7 & less than 5,000 & 1.38 & 1.51 & 1.33 & 1.29 & 1.39 & 1.38 & 1.36 & 1.27 & 1.45 & 1.42 & 1.39 & 1.37 \\
\hline 11 & & 1.28 & 1.36 & 1.22 & 1.17 & 1.26 & 1.23 & 1.23 & 1.17 & 1.28 & 1.31 & 1.30 & 1.25 \\
\hline 12 and 14 & & 1.26 & 1.35 & 1.22 & 1.20 & 1.28 & 1.16 & 1.17 & 1.13 & 1.35 & 1.17 & 1.15 & 1.08 \\
\hline 16 and 17 & & 1.16 & 1.37 & 1.11 & 1.14 & 1.17 & 1.15 & 1.16 & 1.14 & 1.24 & 1.12 & 1.17 & 1.08 \\
\hline $\begin{array}{c}\text { Functional } \\
\text { Class }\end{array}$ & AADT Split & $\begin{array}{c}\text { October } \\
2 \\
\text { Monday } \\
\end{array}$ & $\begin{array}{c}3 \\
\text { Tuesday } \\
\end{array}$ & $\begin{array}{c}4 \\
\text { Wednesday } \\
\end{array}$ & $\begin{array}{c}5 \\
\text { Thursday } \\
\end{array}$ & $\begin{array}{c}\text { November } \\
2 \\
\text { Monday } \\
\end{array}$ & $\begin{array}{c}\mathbf{r} \\
3 \\
\text { Tuesday } \\
\end{array}$ & $\begin{array}{c}4 \\
\text { Wednesday } \\
\end{array}$ & $\begin{array}{c}5 \\
\text { Thursday } \\
\end{array}$ & $\begin{array}{c}\text { December } \\
2 \\
\text { Monday } \\
\end{array}$ & $\begin{array}{c}3 \\
\text { Tuesday } \\
\end{array}$ & $\begin{array}{c}4 \\
\text { Wednesday } \\
\end{array}$ & $\begin{array}{c}5 \\
\text { Thursday } \\
\end{array}$ \\
\hline 1 & greater than 30,000 & 1.16 & 1.13 & 1.13 & 1.08 & 1.16 & 1.28 & 1.23 & 1.38 & 1.34 & 1.39 & 1.34 & 1.58 \\
\hline 1 & less than 30,000 & 1.69 & 1.89 & 1.81 & 1.72 & 1.82 & 1.94 & 1.80 & 1.91 & 2.22 & 2.08 & 2.17 & 1.78 \\
\hline 2 & & 1.30 & 1.18 & 1.19 & 1.17 & 1.31 & 1.28 & 1.28 & 1.22 & 1.29 & 1.22 & 1.24 & 1.23 \\
\hline 6 and 7 & greater than 5,000 & 1.15 & 1.14 & 1.19 & 1.13 & 1.19 & 1.26 & 1.22 & 1.22 & 1.29 & 1.17 & 1.16 & 1.22 \\
\hline 6 and 7 & less than 5,000 & 1.36 & 1.33 & 1.29 & 1.29 & 1.53 & 1.55 & 1.47 & 1.49 & 1.73 & 1.50 & 1.60 & 1.38 \\
\hline 11 & & 1.29 & 1.28 & 1.30 & 1.23 & 1.39 & 1.39 & 1.38 & 1.31 & 1.50 & 1.44 & 1.52 & 1.50 \\
\hline 12 and 14 & & 1.23 & 1.14 & 1.08 & 1.10 & 1.33 & 1.29 & 1.25 & 1.47 & 1.28 & 1.36 & 1.54 & 1.22 \\
\hline 16 and 17 & & 1.15 & 1.09 & 1.09 & 1.13 & 1.12 & 1.14 & 1.14 & 1.34 & 1.18 & 1.13 & 1.11 & 1.17 \\
\hline
\end{tabular}


The procedure for the development of the 1975 factors was presented in Chapter 2. In the 1975 study, the design hourly volume was either the $10^{\text {th }}$ or $30^{\text {th }}$ highest hourly volume. If the AADT was less than or equal to 500 vehicles, the tenth highest hourly volume was used to define the design hourly volume. If the AADT was greater than 500 vehicles, the thirtieth highest hourly volume was used to define the design hourly volume. The resulting values for the PHV to DHV correction factor (B) were presented in Table 2.3.

The similarities between the 1975 and 2001 studies are that they both realized the variability involved in the factors, and attempted to report the factors in the most efficient manner based on this variability. Where the 1975 study reported factors by AADT and by quarter, the current study reported factors for every functional class by day of the month. Although the methods of reporting were different, the magnitude of the factors developed in 1975 and those derived in the 2001 study are similar. The range of the factors developed in 1975 was 0.27 compared to a range of 1.20 for the 2001 factors. This difference can be attributed to the quantity of factors produced. In 1975, eight factors were reported, and in 2001, 384 factors were reported. Interestingly, taking an average of the factors reported yields values of 1.28 and 1.34 for 1975 and 2001, respectively. These values show that overall, the PHV to DHV factors have changed very little in the past 25 years.

The PHV to DHV factors are reported differently from the axle correction factor because of the differences between the two factors. The axle correction factors are mainly 
reported as one factor for the entire year, while the PHV to DHV factors are reported by day of the week by month. This is due to the fact that the axle correction factor reflects the percent trucks on the roadway, which varies little throughout the year, while the PHV to DHV factor is dependant on the overall traffic volume on the roadway, which varies greatly depending on the time of the year. For example, more people travel in the summer months than during the winter.

\subsection{Percent Trucks in the ADT to Percent Trucks in the Peak Hour Factor}

The Percent Trucks in the ADT to Percent Trucks in the Peak Hour factors results are reported in Table 4.4 .

\section{Table 4.4 - Factors Relating Percent Trucks in ADT to Percent Trucks in Peak Hour}

\begin{tabular}{|lc|}
\hline \multicolumn{1}{|c|}{ Grouping } & Factor \\
\hline \hline Rural Heavy Truck Routes & 1.2 \\
Urban Heavy Truck Routes & 1.2 \\
Others & 1.1 \\
\hline
\end{tabular}

Although the factors did not vary between the rural and urban heavy truck routes, they did vary slightly between the heavy truck routes and the other roadways. A lower value for the other roadways shows that a greater percentage of trucks are traveling during the peak hour in these non-heavy truck routes than the roadways identified as heavy truck routes. The relationships of $\%$ trucks in the ADT to \% trucks in the peak hour factors developed by day of the year, by month, and by quarter are included as Appendix $\mathrm{C}$ for informational purposes. 
The factors developed in 1975 relating the \% Trucks ADT to the \% Trucks in the peak hour volume were reported in Table 2.4. These factors are different from those determined in the current study. No mathematical issues could be identified to account

for this difference, other than the fact that in 1975, linear regression analysis was used to develop the factors, and, in the current study, a complete database was used to develop every factor. These factors were then averaged to determine the factor reported. A more probable reason for the difference in the factors would be that more trucks were traveling in the peak hours in 1995-1996 than in 1975. The trend in commerce attributed to "justin-time" inventory discussed earlier causes more trucks to be traveling throughout the day, rather than avoiding the peak hours and traveling throughout the night. Figure 2.1 shows that through truck travel, trucks traveling through an area without making deliveries, stays steady throughout the day while business day truck travel does increase in the peak hours of travel.

\subsection{Percent Trucks in the ADT to Percent Trucks in the Manual Count Hours Factor}

The $\%$ Trucks in the ADT to \% Trucks in the Manual Count Hour factors are shown in Table 4.5 
Table 4.5 - Factors Relating Percent Trucks ADT to Percent Trucks in the Manual Count Hours

\begin{tabular}{|lc|}
\hline Grouping & Factor \\
\hline \hline Rural Heavy Truck Routes & 1.1 \\
Urban Heavy Truck Routes & 1.1 \\
Others & 1.0 \\
\hline
\end{tabular}

The factors indicate that the percent trucks in the ADT on rural and urban heavy truck routes is slightly higher than the percent trucks obtained by performing counts during the manual classification count hours. The factor did not vary between urban and rural heavy truck routes, but did vary slightly for other roadways. On roadways not classified as either a rural heavy truck route or urban heavy truck route, the percent trucks in the traffic stream counted during the manual classification count hours is an accurate estimate of the overall percent trucks in the ADT. The relationships of $\%$ trucks in the ADT to \% trucks in the manual count hours factors developed by day of the year, by month, and by quarter are presented in Appendix D for informational purposes. The West Virginia Division of Highways did not perform this particular analysis in 1975. PENNDOT, however, has developed the data necessary to draw a comparison to this study. Table 4.6 compares the values of the factors developed in this study using West Virginia data and those determined from Pennsylvania data (Bureau of Planning and Research, 2001). Note that the factor developed using PENNDOT data combined rural and urban heavy truck routes. 
Table 4.6 - Comparison of WVDOH 1995-1996 Data and PENNDOT 2001 Data

\begin{tabular}{|l|c|c|}
\hline Factor & WV & Pennsylvania \\
Data & $\begin{array}{c}\text { Data } \\
\mathbf{2 0 0 1}\end{array}$ \\
\hline \hline Rural Heavy Truck Routes (interstates + 1 minor arterial) & 1.1 & 1.26 \\
Urban Heavy Truck Routes (interstates) & 1.1 & 1.0 \\
\cline { 3 - 3 } Others & 1.0 & 0.91 \\
\hline
\end{tabular}

The factors developed for heavy truck routes in Pennsylvania were higher than those developed in West Virginia with a difference of $13 \%$, but they are on the same order of magnitude. It should be noted that the values reported for Pennsylvania were not actual factors computed by PENNDOT. The author determined the factors used for the comparison by using tabular data values of percent of vehicles and percent of trucks traveling during each hour of the day for the different Pennsylvania roadway classifications. These factors were then related to corresponding values reported for percent trucks for the same roadway classifications. For this reason, the Pennsylvania values are highly subject to variability due to rounding. Also, the factors are not compiled by site then aggregated; they are generalities that are combined together. 


\section{Chapter 5 CONCLUSIONS AND RECOMMENDATIONS}

\subsection{Conclusions}

The factors developed as part of this study were derived using data collected in 1995 and 1996 from West Virginia's 52 permanent count stations. The data provided from these counters was reviewed and erroneous data were removed in order to ensure validity of the raw data from the count stations.

A key limitation of the study was that about $25 \%$ of the total data from the 52 permanent traffic recorders was either missing or in error with some sites up to $81 \%$ missing and/or in error. A notable finding relating to the missing data occurred during the aggregation of the factors. When determining whether or not there was a significant difference in the factors developed by day of the month, there were too many factors missing to perform an ANOVA analysis.

The results of this study are valid for use in West Virginia and can be utilized throughout the state with confidence. The limitation of the factors derived by this study is that they should only be used to adjust short-term counts performed in West Virginia. This limitation is noted for the reason that the raw data collected at West Virginia permanent count stations was used in the development of the factors. These factors, however, can be applied for all roadways in West Virginia, for the permanent count stations used in the

collection of the raw data were located throughout the state. The factors developed in this report replace those developed in 1975 to more accurately estimate current traffic 
characteristics. Overall, the factors developed using the 52 permanent count stations in West Virginia are consistent with those factors developed in 1975 by the WVDOH. The changes encountered were consistent with the changing trends of truck travel.

An axle correction factor was developed as part of this study to be applied to (short-term) axle counts. Applying an axle correction factor transforms the number of axles counted by the short-term count into the traffic volume that traveled over the counter. Due to variability determined by ANOVA analysis, factors were reported for each of six different functional classification groupings. The factor developed for functional class 1 contained variability in the first quarter significant enough to necessitate that a separate factor be reported for this quarter, with another factor representing the last three quarters of the year. Factors for the other functional class groupings were reported as one factor for the entire year.

Factors relating PHV to DHV were developed so that the peak hour volume experienced on a roadway during the peak hour of the day determined by a short-term count could be used with the factor to estimate the design hour volume. Due to the high variability experienced within the different time groupings, the factors were reported by day of the month for the 6 roadway functional classification groupings. Due to significant differences with in the factors with respect to AADT, divisions were made in the groups where AADT was a source of variation.

Factors relating percent trucks in ADT to percent trucks in peak hour were developed based on three groupings: 1) urban heavy truck routes, 2) rural heavy truck routes, and 3) 
other roadways. These factors are to be used to adjust the percent trucks during the peak hour volume of the short-term counts to more accurately estimate the percentage of trucks in the average daily traffic. Similarly, factors relating percent trucks ADT to percent trucks in the manual count hours were developed based on the same three groupings. These factors are to be used to adjust the percent trucks experienced during the manual classification count hours to more accurately estimate the percentage of trucks in the average daily traffic.

Due to changing travel patterns, particularly for commercial vehicles, and demographics in West Virginia over the past 25 years, the factors developed in this study are meant to replace those factors developed in 1975. The axle correction factors based on 1995-96 data are similar to those from 1975. The changes are consistent with the increased travel of heavy trucks on the interstates that has occurred in the last 25 years. The factors relating to axle correction were significantly different only with respect to functional class 1 (rural interstates), namely the first quarter of the year. For this reason, one factor was reported for the first quarter functional class 1, and one factor was reported grouping the last three quarters of the year. All other functional classes showed no significant difference throughout the year, thus one factor was reported for each class for the year.

The PHV to DHV factors were reported by day of the month for each functional classification with significant variability due to AADT accounted for, rather than the 1975 method of reporting the factors by quarter and AADT alone. The factors in this 
study were reported in this fashion due to the significant difference found while performing ANOVA analysis.

The factors relating percent trucks in ADT to percent trucks in peak hour were somewhat different than those reported in 1975. This difference is consistent with a greater percentage of trucks traveling during the peak hour of the day. The factors were reported by rural truck route, urban truck route, or other, as opposed to the 1975 method of reporting the factors by quarter for all classes of roadways. Factors relating percent trucks in the ADT to percent trucks in the manual count hours were not developed in 1975. This factor is to be used to adjust the percentage of trucks counted during the manual classification count hours of 7am-10am, 11am-1pm, and 2pm-6pm.

The factors relating percent trucks in ADT to percent trucks in peak hour, and factors relating percent trucks ADT to percent trucks in the manual count hours showed variability only in terms of heavy and non-heavy truck routes. For this reason, factors were reported based on the routes labeled as either rural heavy truck route, urban heavy truck route, and all other sites combined.

The factors relating peak hour volume to design hour volume yielded many significant differences. For this reason, the factors were reported in a more detailed fashion than the other factors, i.e., by day of the month. 


\subsection{Recommendations}

The recommendation of the research not specific to the factors that were developed include the following:

1. Update these factors periodically to validate the current factors used and to identify new trends that may be developing on West Virginia's roadways. PENNDOT for example, develops similar factors every year.

2. Inspect the permanent count stations on a regular basis and perform maintenance and repair to the recorders to improve data quality. Troubleshooting could be performed to identify the special causes of error.

\subsection{Implementation}

The factors developed herein will be immediately useful to persons analyzing traffic count data in West Virginia. The axle correction factors are critical when machine counts are collected with pneumatic tube counters. Furthermore, since continuous 365 day counts are available only at the permanent stations, the PHV to DHV factors will be heavily used by highway designers, traffic engineers, and other practitioners in the planning and design of projects statewide. Lastly, the truck percentage factors have numerous applications, and will be used by a wide variety of practitioners. They can be used to maximize the value of short-term truck counts in projecting total daily truck traffic, which will be useful in both planning and design. In addition to being distributed within the WVDOH, these factors should be made available to consultants, MPOs, and other local entities concerned with transportation planning 
data collection and analysis. Using the factors developed in this study, the aforementioned agencies will be able to:

- Apply an axle correction factor to a short-term pneumatic tube axle count to determine a more accurate traffic volume.

- Determine the design hourly volume (DHV) by measuring the peak hour volume and applying the appropriate PHV to DHV factor.

- Determine the percent trucks in the average daily traffic on a roadway by determining the percentage of trucks in the peak hour and applying the appropriate \% trucks in the ADT to \% trucks in the peak hour factor.

- Determine the percent trucks in the average daily traffic on a roadway by measuring the percentage of trucks in the manual count hours and applying the appropriate \% trucks in the ADT to \% trucks in the manual count hours factor. 


\section{REFERENCE LIST}

American Association of State Highway and Transportation Officials, AASHTO

Guidelines for Traffic Data Programs, Joint Task Force on Traffic Monitoring

Standards of the AASHTO Highway Subcommittee on Traffic Engineering, Washington, D.C., 1992.

American Association of State Highway and Transportation Officials, $\underline{\text { A Policy on }}$ Geometric Design of Highways and Streets, 2001, Washington, D.C., 2001.

Bureau of Transportation Planning, Annual Average Daily Traffic (AADT) Development Procedures Documentation, Michigan Department of Transportation, July 2000.

Bureau of Planning and Research, 2000 Pennsylvania Traffic Data, Pennsylvania Department of Transportation, Harrisburg, PA, August 2001.

Bureau of Planning and Research, Pennsylvania Traffic Data 1998, Pennsylvania Department of Transportation, Harrisburg, PA, July 1999.

Federal Highway Administration, Traffic Monitoring Guide, Office of Highway Policy Information, Washington, D.C., January 2001.

Sharma, Satish C; Oh, Jin Y, "Prediction of Design Hour Volume as a Function of Amount and Nature of Travel", ITE Journal, Volume 58, Issue 2, Washington, D.C., 1988, pages 19-24.

Traffic Analysis Section, Determination of a Truck Adjustment Factor for ATR's, Advanced Planning Division, West Virginia Department of Highways, Charleston, WV, May 1975.

Traffic Analysis Section, Development of a Method of Estimating Design Hour Volume, Advanced Planning Division, West Virginia Department of Highways, Charleston, WV, December 1975.

Traffic Analysis Section, The Relationship of the Percentage of Trucks in the Average Daily Traffic to the Percentage of Trucks in the Peak Hour Volume, Advanced Planning Division, West Virginia Department of Highways, Charleston, WV, February 1975.

Walters, Carol H.; Poe, Christopher M., "Development of Appropriate Design-Hour Volumes for Urban Freeways in Large Texas Cities", Transportation Research Record 1320, Washington, D.C., 1991, pages 32-39. 


\section{APPENDIX A}

AXLE CORRECTION FACTOR SUMMARIES BY DAY OF THE YEAR, BY MONTH, AND BY QUARTER 
Axle By Day Correction Factor Summary - By Day Regardless of Month

\begin{tabular}{ccccc}
$\begin{array}{c}\text { Functional } \\
\text { Class }\end{array}$ & Monday & Tuesday & Wednesday & Thursday \\
\hline \hline & & & & \\
1 & 0.81 & 0.76 & 0.76 & 0.78 \\
2 & 0.92 & 0.92 & 0.92 & 0.92 \\
6,7 & 0.95 & 0.94 & 0.94 & 0.94 \\
11 & 0.85 & 0.82 & 0.81 & 0.82 \\
12,14 & 0.96 & 0.95 & 0.95 & 0.95 \\
16,17 & 0.99 & 0.99 & 0.99 & 0.99
\end{tabular}

Minimum Maximum Range

$\begin{array}{lll}0.76 & 0.81 & 0.04 \\ 0.92 & 0.92 & 0.01 \\ 0.94 & 0.95 & 0.01 \\ 0.81 & 0.85 & 0.04 \\ 0.99 & 0.99 & 0.00\end{array}$

Axle by Month Factors

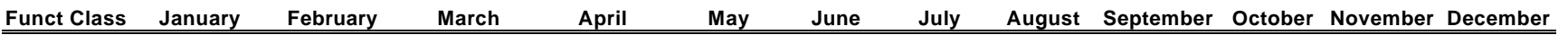

$\begin{array}{ccccccccccccc}1 & 0.75 & 0.74 & 0.74 & 0.77 & 0.78 & 0.79 & 0.82 & 0.80 & 0.78 & 0.77 & 0.81 & 0.81 \\ 2 & 0.93 & 0.91 & 0.90 & 0.90 & 0.92 & 0.92 & 0.93 & 0.92 & 0.91 & 0.91 & 0.93 & 0.91 \\ 6,7 & 0.94 & 0.94 & 0.91 & 0.94 & 0.95 & 0.96 & 0.95 & 0.94 & 0.94 & 0.94 & 0.94 & 0.94 \\ 11 & 0.81 & 0.80 & 0.82 & 0.82 & 0.82 & 0.82 & 0.85 & 0.84 & 0.83 & 0.82 & 0.83 & 0.83 \\ 12,14 & 0.95 & 0.95 & 0.95 & 0.95 & 0.95 & 0.95 & 0.95 & 0.95 & 0.95 & 0.96 & 0.96 & 0.96 \\ 16,17 & 0.99 & 0.99 & 0.99 & 0.99 & 0.99 & 0.99 & 0.99 & 0.99 & 0.99 & 0.99 & 0.99 & 0.99\end{array}$

Axle by Quarter

Funct Class 1st Quarter 2nd Quarter 3rd Quarter 4th Quarter

$\begin{array}{ccccc}1 & 0.74 & 0.78 & 0.81 & 0.80 \\ 2 & 0.92 & 0.92 & 0.92 & 0.92 \\ 6,7 & 0.94 & 0.94 & 0.94 & 0.94 \\ 11 & 0.81 & 0.83 & 0.84 & 0.83 \\ 12,14 & 0.95 & 0.96 & 0.95 & 0.96 \\ 16,17 & 0.99 & 0.99 & 0.99 & 0.99\end{array}$

$\underline{\text { Minimum Maximum Range }}$

$\begin{array}{lll}0.74 & 0.81 & 0.06 \\ 0.92 & 0.92 & 0.00 \\ 0.94 & 0.94 & 0.00 \\ 0.81 & 0.84 & 0.02 \\ 0.95 & 0.96 & 0.01 \\ 0.99 & 0.99 & 0.00\end{array}$




\section{APPENDIX B}

PHV TO DHV FACTOR SUMMARIES BY DAY OF THE YEAR, BY MONTH, AND BY QUARTER 
DHV By Day Correction Factor Summary - By Day Regardless of Month

Functional

$$
\begin{gathered}
\begin{array}{c}
\text { Functional } \\
\text { Class }
\end{array} \\
\hline \hline
\end{gathered}
$$

Monday Tuesday Wednesday Thursday

$\begin{array}{cc}1 & \text { greater than } 30,000 \\ 2 & \text { less than } 30,000 \\ 6 \text { and } 7 & \text { greater than } 5,000 \\ 6 \text { and } 7 & \text { less than } 5,000 \\ 11 & \\ 12,14 & \\ 16,17 & \end{array}$

DHV by Month Factors

Funct Class

$\begin{array}{ccc}1 & \text { greater than } 30,000 & 1.27 \\ & \text { less than } 30,000 & 2.17 \\ 2 & & 1.38 \\ 6 \text { and } 7 & \text { greater than } 5,000 & 1.30 \\ 6 \text { and } 7 & \text { less than } 5,000 & 1.54 \\ 11 & & 1.45 \\ 12,14 & & 1.22 \\ 16,17 & & 1.21\end{array}$

DHV by Quarter

Funct Class

1st Quarter 2nd Quarter 3rd Quarter 4th Quarter

$\begin{array}{cccccc}1 & & & & & \\ & \text { greater than } 30,000 & 1.29 & 1.18 & 1.45 & 1.27 \\ 2 & \text { less than 30,000 } & 2.10 & 1.71 & 1.66 & 1.90 \\ 6 \text { and } 7 & \text { greater than } 5,000 & 1.34 & 1.20 & 1.24 & 1.24 \\ 6 \text { and } 7 & \text { less than 5,000 } & 1.25 & 1.18 & 1.19 & 1.19 \\ 11 & & 1.50 & 1.46 & 1.38 & 1.46 \\ 12,14 & & 1.35 & 1.26 & 1.38 \\ 16,17 & & 1.16 & 1.10 & 1.24 & 1.18 \\ & & 1.18 & 1.12 & 1.17 & 1.16\end{array}$

Minimum Maximum Range

$\begin{array}{lll}1.26 & 1.38 & 0.12 \\ 1.74 & 1.92 & 0.17 \\ 1.21 & 1.32 & 0.11 \\ 1.19 & 1.22 & 0.03 \\ 1.40 & 1.50 & 0.10 \\ 1.32 & 1.40 & 0.07 \\ 1.12 & 1.28 & 0.16 \\ 1.14 & 1.19 & 0.05\end{array}$

Minimum Maximum Range

$\begin{array}{lll}1.12 & 2.07 & 0.95 \\ 1.63 & 2.23 & 0.60 \\ 1.18 & 1.39 & 0.20 \\ 1.15 & 1.30 & 0.15 \\ 1.32 & 1.67 & 0.36 \\ 1.22 & 1.53 & 0.31 \\ 1.07 & 1.36 & 0.29 \\ 1.11 & 1.21 & 0.10\end{array}$

Minimum Maximum Range

$\begin{array}{lll}1.18 & 1.45 & 0.27 \\ 1.66 & 2.10 & 0.45 \\ 1.20 & 1.34 & 0.14 \\ 1.18 & 1.25 & 0.08 \\ 1.38 & 1.57 & 0.19 \\ 1.26 & 1.50 & 0.24 \\ 1.10 & 1.24 & 0.14 \\ 1.12 & 1.18 & 0.06\end{array}$




\section{APPENDIX C}

PERCENT TRUCKS IN ADT TO PERCENT TRUCKS IN THE PEAK HOUR

FACTOR SUMMARIES BY DAY OF THE YEAR, BY MONTH, AND BY QUARTER 
Truck PH Correction Factor Summary - By Day Regardless of Month

Grouping

Monday Tuesday Wednesday Thursday

Rural Heavy Truck Routes Urban Heavy Truck Routes

1.15
1.19

1.16

$\begin{array}{lll}1.16 & 1.20 & 1.18 \\ 1.21 & 1.18 & 1.21 \\ 1.13 & 1.08 & 1.09\end{array}$

Truck PH by Month Factors

\section{Grouping}

January February

March

April

May

June

Rural Heavy Truck Routes

Urban Heavy Truck Route

1.17

1.18

1.19

1.18

Other

$\begin{array}{ll}1.18 & 1.20 \\ 1.09 & 1.10\end{array}$

1.23

1.24

1.18

1.16
1.19

July

1.17

1.17
1.19

$\begin{array}{rrrr} & & & \\ & & & \\ & & & \\ 1.15 & 1.17 & 1.17 & 1.17 \\ 1.26 & 1.22 & 1.15 & 1.18 \\ 1.09 & 1.10 & 1.10 & 1.20\end{array}$

Truck PH by Quarter

Grouping

1st Quarter 2nd Quarter 3rd Quarter 4th Quarter

$\begin{array}{lllll}\text { Rural Heavy Truck Routes } & 1.17 & 1.18 & 1.16 & 1.20 \\ \text { Urban Heavy Truck Routes } & 1.20 & 1.21 & 1.20 & 1.18 \\ \text { Other } & 1.09 & 1.11 & 1.11 & 1.13\end{array}$

Minimum Maximum Range

$\begin{array}{lll}1.15 & 1.20 & 0.05 \\ 1.18 & 1.21 & 0.03 \\ 1.08 & 1.13 & 0.05\end{array}$

Minimum Maximum Range

$\begin{array}{lll}1.15 & 1.19 & 0.04\end{array}$

$\begin{array}{lll}1.15 & 1.19 & 0.04 \\ 1.14 & 1.26 & 0.12 \\ 1.07 & 1.20 & 0.13\end{array}$

$1.20 \quad 0.13$

Minimum Maximum Range

$\begin{array}{lll}1.16 & 1.20 & 0.04 \\ 1.18 & 1.21 & 0.03 \\ 1.09 & 1.13 & 0.04\end{array}$




\section{APPENDIX D}

\section{PERCENT TRUCKS IN ADT TO PERCENT TRUCKS IN THE MANUAL COUNT}

HOUR FACTOR SUMMARIES BY DAY OF THE YEAR, BY MONTH, AND BY

QUARTER 
Truck MC Correction Factor Summary - By Day Regardless of Month

Grouping

Monday Tuesday Wednesday Thursday

Rural Heavy Truck Route

Urban Heavy Truck Route

1.11

$\begin{array}{ll}1.11 & 1.13 \\ 1.08 & 1.06\end{array}$

1.13
1.06

1.10

$\begin{array}{llll}0.97 & 0.98 & 0.96 & 0.97\end{array}$

0.97

Truck MC by Month Factors

\section{Grouping}

January

February

March

April

May

June

July

August September October November December

Rural Heavy Truck Route

Urban Heavy Truck Route

$\begin{array}{ll}1.12 & 1.12 \\ 1.06 & 1.09 \\ 0.98 & 0.98\end{array}$

$\begin{array}{ll}1.12 & 1.12 \\ 1.08 & 1.08\end{array}$

$1.09 \quad 1.12$

$1.12 \quad 1.05$
1.08

$1.05 \quad 1.11$

1.11
1.08

$\begin{array}{ll}1.11 & 1.18 \\ 1.09 & 1.09\end{array}$

1.18
1.09
0.98

1.10
1.03
0.96

1.08
1.07
0.94

1.07
0.94

$0.97 \quad 0.96$

0.96

Truck MC by Quarter

\section{Grouping}

1st Quarter 2nd Quarter 3rd Quarter 4th Quarter

Rural Heavy Truck Route

Urban Heavy Truck Route

1.12

1.1
1.04

1.11
1.04
0.97

1.09
1.07

1.07
0.97

1.11
1.06

1.06

0.98

$\begin{array}{lll}0.97 & 0.97 & 0.96\end{array}$

Minimum Maximum Range

$\begin{array}{lll}1.09 & 1.12 & 0.03 \\ 1.04 & 1.08 & 0.03\end{array}$

$\begin{array}{lll}0.96 & 0.98 & 0.02\end{array}$




\section{APPENDIX E}

\section{FACTORS DEVELOPED USING ONLY FRIDAY,}

SATURDAY, AND SUNDAY DATA 
Axle By Day Correction Factor Summary - By Day Regardless of Month

Functional

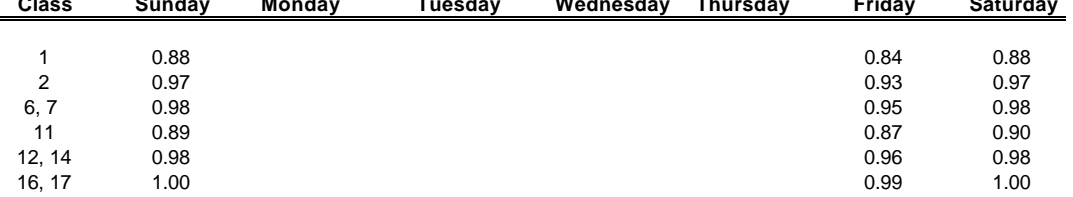

Minimum Maximum Range

$\begin{array}{lll}0.84 & 0.88 & 0.04 \\ 0.93 & 0.97 & 0.04 \\ 0.95 & 0.98 & 0.03 \\ 0.87 & 0.90 & 0.03 \\ 0.96 & 0.98 & 0.03 \\ 0.99 & 1.00 & 0.00\end{array}$

Axle by Month Factors

\begin{tabular}{cccccccccccc} 
Funct Class & January & February & March & April & May & June & July & August & September & October & November December \\
\hline \hline & & & & & & & & & & & \\
\end{tabular}

Minimum Maximum Range

$\begin{array}{lll}0.81 & 0.89 & 0.08 \\ 0.94 & 0.96 & 0.02 \\ 0.95 & 0.98 & 0.03 \\ 0.86 & 0.90 & 0.05 \\ 0.96 & 0.98 & 0.02 \\ 0.99 & 1.00 & 0.00\end{array}$

Axle by Quarter

Funct Class 1st Quarter 2nd Quarter 3rd Quarter 4th Quarter

$\begin{array}{ccccc}1 & 0.83 & 0.87 & 0.89 & 0.88 \\ 2 & 0.95 & 0.96 & 0.96 & 0.96 \\ 6,7 & 0.96 & 0.97 & 0.97 & 0.97 \\ 11 & 0.87 & 0.89 & 0.90 & 0.89 \\ 12,14 & 0.97 & 0.98 & 0.97 & 0.98 \\ 16,17 & 1.00 & 1.00 & 0.99 & 1.00\end{array}$

Minimum Maximum Range

$\begin{array}{lll}0.83 & 0.89 & 0.06 \\ 0.95 & 0.96 & 0.00 \\ 0.96 & 0.97 & 0.01 \\ 0.87 & 0.90 & 0.03 \\ 0.97 & 0.98 & 0.01 \\ 0.99 & 1.00 & 0.00\end{array}$

\begin{tabular}{|c|c|c|c|}
\hline \multicolumn{3}{|c|}{ Friday } \\
Functional Class & 1st Quarter & Rest of Year & Entire Year \\
\hline \hline 1 & 0.80 & 0.85 & \\
2 & & & 0.93 \\
6,7 & & & 0.95 \\
11 & & & 0.87 \\
12,14 & & & 0.96 \\
16,17 & & 0.99 \\
\hline
\end{tabular}

\begin{tabular}{|c|c|c|c|}
\hline \multicolumn{3}{|c|}{ Saturday-Sunday } \\
Functional Class & 1st Quarter & Rest of Year & Entire Year \\
\hline \hline 1 & 0.84 & 0.89 & \\
2 & & & 0.97 \\
6,7 & & & 0.98 \\
11 & & & 0.90 \\
12,14 & & & 0.98 \\
16,17 & & & 1.00 \\
\hline
\end{tabular}


PHV-DHV Factor Summary - By Day Regardless of Month

Functional

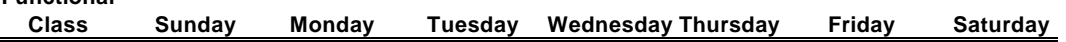

$\begin{array}{cccc}1 & 1.48 & 1.35 & 1.67 \\ 2 & 1.99 & 1.53 & 2.02 \\ 6,7 & 1.43 & 1.17 & 1.41 \\ 11 & 1.49 & 1.21 & 1.52 \\ 12,14 & 1.67 & 1.09 & 1.63 \\ 16,17 & 1.53 & 1.12 & 1.42\end{array}$

Minimum Maximum Range

PHV-DHV by Month Factors

\begin{tabular}{|c|c|c|c|c|c|c|c|c|c|c|c|c|}
\hline Funct Class & January & February & March & April & May & June & July & August & September & October & $\begin{array}{l}\text { November } \\
\end{array}$ & December \\
\hline 1 & 2.14 & 1.97 & 1.42 & 1.32 & 1.37 & 1.29 & 1.35 & 1.16 & 1.30 & 1.41 & 1.44 & 1.79 \\
\hline 2 & 2.61 & 3.27 & 2.01 & 1.96 & 1.69 & 1.67 & 1.66 & 1.71 & 1.66 & 1.62 & 1.78 & 1.88 \\
\hline 6,7 & 1.69 & 1.51 & 1.31 & 1.30 & 1.26 & 1.27 & 1.26 & 1.27 & 1.27 & 1.23 & 1.34 & 1.39 \\
\hline 11 & 1.82 & 1.90 & 1.45 & 1.32 & 1.36 & 1.23 & 1.16 & 1.18 & 1.31 & 1.27 & 1.30 & 1.53 \\
\hline 12,14 & 1.90 & 1.61 & 1.25 & 1.32 & 1.37 & 1.35 & 1.43 & 1.35 & 1.33 & 1.33 & 1.39 & 1.37 \\
\hline 16,17 & 1.57 & 1.21 & 1.10 & 1.29 & 1.26 & 1.31 & 1.39 & 1.40 & 1.36 & 1.33 & 1.46 & 1.43 \\
\hline
\end{tabular}

Minimum Maximum Range

$\begin{array}{lll}1.16 & 2.14 & 0.98 \\ 1.62 & 3.27 & 1.65 \\ 1.23 & 1.69 & 0.46 \\ 1.16 & 1.90 & 0.74 \\ 1.25 & 1.90 & 0.66 \\ 1.10 & 1.57 & 0.47\end{array}$

PHV-DHV by Quarter

Funct Class 1st Quarter 2nd Quarter 3rd Quarter 4th Quarter

$\begin{array}{ccccc}1 & 1.88 & 1.33 & 1.25 & 1.55 \\ 2 & 2.34 & 1.71 & 1.68 & 1.76 \\ 6,7 & 1.53 & 1.27 & 1.26 & 1.32 \\ 11 & 1.76 & 1.30 & 1.22 & 1.37 \\ 12,14 & 1.68 & 1.38 & 1.37 & 1.36 \\ 16,17 & 1.32 & 1.29 & 1.38 & 1.41\end{array}$

Minimum Maximum Range

$\begin{array}{lll}1.25 & 1.88 & 0.63 \\ 1.68 & 2.34 & 0.67 \\ 1.26 & 1.53 & 0.26 \\ 1.22 & 1.76 & 0.55 \\ 1.36 & 1.68 & 0.32 \\ 1.29 & 1.41 & 0.12\end{array}$


Truck PH Correction Factor Summary - By Day Regardless of Month

Grouping

Sunday Monday

Tuesday

Wednesday

Thursday Friday Saturday

Rural Heavy Truck Routes $\quad 1.13$

$\begin{array}{ll}\text { Urban Heavy Truck Route } & 1.11 \\ \text { Other } & 1.10\end{array}$

$\begin{array}{ll}1.16 & 1.11 \\ 1.18 & 1.11 \\ 1.07 & 1.01\end{array}$

$\begin{array}{ll}1.18 & 1.11 \\ 1.07 & 1.01\end{array}$

Truck PH by Month Factors

\begin{tabular}{|c|c|c|c|c|c|c|c|c|c|c|c|c|}
\hline Grouping & January & February & March & April & May & June & July & August & September & October & November & December \\
\hline Rural Heavy Truck Routes & 1.15 & 1.19 & 1.17 & 1.17 & 1.16 & 1.10 & 1.06 & 1.13 & 1.09 & 1.18 & 1.13 & 1.12 \\
\hline Urban Heavy Truck Route & 1.07 & 1.15 & 1.17 & 1.18 & 1.14 & 1.17 & 1.10 & 1.14 & 1.11 & 1.18 & 1.08 & 1.11 \\
\hline Other & 0.99 & 1.05 & 1.08 & 1.04 & 1.13 & 1.05 & 1.06 & 1.02 & 1.08 & 1.05 & 0.99 & 1.03 \\
\hline
\end{tabular}

\section{Truck PH by Quarter Factors}

\begin{tabular}{|c|c|c|c|c|c|}
\hline Grouping & 1st Quarter & 2nd Quarter & 3rd Quarter & 4th Quarter & \\
\hline Rural Heavy Truck Routes & 1.17 & 1.14 & 1.09 & 1.14 & \\
\hline Urban Heavy Truck Route & 1.12 & 1.19 & 1.12 & 1.13 & \\
\hline \multirow[t]{5}{*}{ Other } & 1.03 & 1.11 & 1.05 & 1.02 & \\
\hline & & & & Friday & Saturday, Sunday \\
\hline & & & Rural Truck Route & 1.2 & 1.1 \\
\hline & & & Urban Truck Route & 1.2 & 1.1 \\
\hline & & & Other & 1.1 & 1.1 \\
\hline
\end{tabular}

Minimum Maximum Range

$\begin{array}{lll}1.11 & 1.16 & 0.05 \\ 1.11 & 1.18 & 0.07\end{array}$

\section{Minimum Maximum Range}

$\begin{array}{lll}1.09 & 1.17 & 0.07 \\ 1.12 & 1.19 & 0.07 \\ 1.02 & 1.11 & 0.10\end{array}$

$\begin{array}{lll}1.02 & 1.11 & 0.10\end{array}$


Truck MC Correction Factor Summary - By Day Regardless of Month

\begin{tabular}{|c|c|c|c|c|c|c|c|}
\hline Grouping & Sunday & Monday & Tuesday & Wednesday & Thursday & Friday & Saturday \\
\hline Rural Heavy Truck Routes & 1.09 & & & & & 1.07 & 1.06 \\
\hline Urban Heavy Truck Routes & & & & & & 1.03 & 1.04 \\
\hline Other & 0.99 & & & & & 0.95 & 0.97 \\
\hline
\end{tabular}

Minimum Maximum Range

$\begin{array}{lll}1.06 & 1.09 & 0.03 \\ 1.03 & 1.04 & 0.00\end{array}$

$\begin{array}{lll}1.06 & 1.09 & 0.03 \\ 0.95 & 0.99 & 0.04\end{array}$

Truck MC by Month Factors

\begin{tabular}{|c|c|c|c|c|c|}
\hline Grouping & January & February & March & April & May \\
\hline $\begin{array}{l}\text { Rural Heavy Truck Routes } \\
\text { Urban Heavy Truck Routes } \\
\text { Other }\end{array}$ & $\begin{array}{l}1.08 \\
1.00 \\
0.97\end{array}$ & $\begin{array}{l}1.08 \\
1.06 \\
0.98\end{array}$ & $\begin{array}{l}1.10 \\
1.06 \\
0.98\end{array}$ & $\begin{array}{l}1.09 \\
1.07 \\
0.99\end{array}$ & $\begin{array}{l}1.08 \\
1.06 \\
0.97\end{array}$ \\
\hline \multicolumn{6}{|l|}{ Truck MC by Quarter } \\
\hline Grouping & 1st Quarter & 2nd Quarter & 3rd Quarter & 4th Quarter & \\
\hline $\begin{array}{l}\text { Rural Heavy Truck Routes } \\
\text { Urban Heavy Truck Routes } \\
\text { Other }\end{array}$ & $\begin{array}{l}1.09 \\
1.03 \\
0.98\end{array}$ & $\begin{array}{l}1.08 \\
1.06 \\
0.98\end{array}$ & $\begin{array}{l}1.06 \\
1.05 \\
0.98\end{array}$ & $\begin{array}{l}1.06 \\
1.04 \\
0.96\end{array}$ & \\
\hline \multirow{2}{*}{ Other } & & & & \multicolumn{2}{|c|}{ Friday, Saturday, and Sunday } \\
\hline & & & $\begin{array}{l}\text { Rural Truck Route } \\
\text { Urban } \\
\text { Other }\end{array}$ & $\begin{array}{l}1.1 \\
1.0 \\
1.0\end{array}$ & \\
\hline
\end{tabular}

Minimum Maximum Range

$\begin{array}{lll}1.03 & 1.10 & 0.07 \\ 1.00 & 1.07 & 0.07\end{array}$

$\begin{array}{lll}1.00 & 1.07 & 0.07 \\ 0.93 & 0.99 & 0.05\end{array}$

Minimum Maximum Range

$\begin{array}{lll}1.06 & 1.09 & 0.03 \\ 1.03 & 1.06 & 0.02 \\ 0.96 & 0.98 & 0.02\end{array}$

